NIST Advanced Manufacturing Series 100-19

\title{
The Effects of Laser Powder Bed Fusion Process Parameters on Material Hardness and Density for Nickel Alloy 625
}

Christopher U. Brown

Gregor Jacob

Antonio Possolo Carlos Beauchamp

Max Peltz

Mark Stoudt

Alkan Donmez

This publication is available free of charge from:

https://doi.org/10.6028/NIST.AMS.100-19

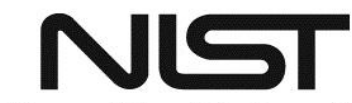

National Institute of Standards and Technology U.S. Department of Commerce 


\title{
The Effects of Laser Powder Bed Fusion Process Parameters on Material Hardness and Density for Nickel Alloy 625
}

\author{
Christopher U. Brown \\ Gregor Jacob* \\ Antonio Possolo \\ Carlos Beauchamp \\ Max Peltz \\ Mark Stoudt \\ Alkan Donmez \\ Engineering Laboratory
}

*Currently with Citim GmbH, Barleben, Germany

This publication is available free of charge from:

https://doi.org/10.6028/NIST.AMS.100-19

August 2018

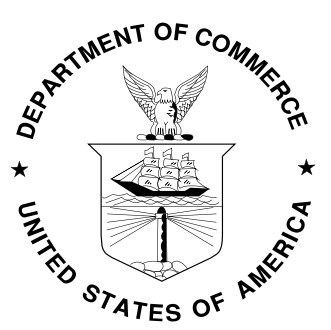

U.S. Department of Commerce

Wilbur L. Ross, Jr., Secretary

National Institute of Standards and Technology Walter Copan, NIST Director and Undersecretary of Commerce for Standards and Technology 


\begin{abstract}
The goal of this study was to investigate the relationship between mechanical and material properties (including density) of manufactured nickel super alloy (IN625) using a laser powder bed fusion process and three process parameters: laser power, hatch distance, and scan speed. Hardness of the manufactured blocks was measured as a representative of the mechanical properties. Density measurements were carried out using the pyncometry method. Three sets of blocks were manufactured using IN625 metal powder (nitrogen gas atomized) on a laser powder bed fusion machine. Different combinations of process parameters yielded different energy densities for each block for the three builds. The laser scan speed, laser power, hatch distance, and energy density all had statistically significant relationships with hardness. The average bulk density increased non-linearly with increasing values of energy density. A similar trend was in the hardness data. The results of this study served as a guide to determine the range of parameters yielding acceptable material properties for the investigation of process parameter sensitivities during a subsequent IN625 round robin study.
\end{abstract}

Keywords: Additive Manufacturing; Energy Density; Hardness; Hatch Distance; Laser Power; Scan Speed; Selective Laser Melting; Superalloys. 
Table of Contents

1. Introduction 1

1.1. Changing Layer Thickness 2

1.2. Changing Scan Speed 2

1.3 Changing Hatch Distance 3

1.4. Changing Laser Power 4

$\begin{array}{ll}\text { 2. Experimental Method } & 7\end{array}$

3. Results / Discussion $\quad 11$

3.1. Hardness 11

3.2. Bulk Density 29

$\begin{array}{ll}\text { 4. Conclusions } & 31\end{array}$

$\begin{array}{ll}\text { References } & 33\end{array}$

Appendix A: Build Drawing and Build Report for Build \#2-16 35

Appendix B: Build Drawing and Build Report for Build \#3-16 39

Appendix C: Build Drawing and Build Report for Build \#17-16 43

Appendix D: The Effect of Block Thickness on Hardness Measurements 48

Appendix E: Microstructure of Manufactured Material $\quad 50$ 


\section{Introduction}

There are many potentially influencing parameters for laser powder bed fusion (LPBF) processes for additively manufacturing (AM) parts. A subset of these parameters is used to determine the energy density applied to the powder layer during the LPBF process. Energy density $\left(E_{\mathrm{D}}\right)$ is a function of laser power $(P)$, scan speed $(v)$ of the laser beam, the powder layer thickness $(t)$, and the hatch distance ( $h$, distance between scan lines).

$$
E_{\mathrm{D}}=\frac{P}{h \cdot t \cdot v}\left[\mathrm{~J} \cdot \mathrm{mm}^{-3}\right]
$$

The effects of process parameters on the material properties manufactured by LPBF are of significant interest by users of this technology. ${ }^{1}$ Beyond process recipes provided by the machine vendors, understanding the process parameters that result in 'acceptable' material properties helps users optimize their manufacturing plans.

The goal of this study was to investigate the relationship between the mechanical and material properties (including bulk density) of an additively manufactured nickel-based super alloy (IN625) using a laser powder bed fusion process and three process parameters: laser power, hatch distance, and scan speed. In an effort to choose the range of parameter settings for a future AM round robin study to be coordinated by the National Institute of Standards and Technology (NIST), this study was conducted using three sets of manufactured IN625 blocks with each set built on a single build plate. Each block was manufactured with a specific process parameter set (hatch distance, layer thickness, laser power, and/or scan speed) that resulted in a range of energy density values during manufacturing. The build plates with the blocks were heat treated first, and the blocks were separated from the build plates later. Rockwell hardness of each block was measured after separation.

\footnotetext{
${ }^{1}$ Certain commercial entities, equipment, or materials may be identified in this document in order to describe an experimental procedure or concept adequately. Such identification is not intended to imply recommendation or endorsement by the National Institute of Standards and Technology, nor is it intended to imply that the entities, materials, or equipment are necessarily the best available for the purpose.
} 
Many studies have been conducted to determine the effects of various LPBF process settings on the mechanical and material properties of the resulting part. The following samples of those studies were grouped by process parameters that were considered.

\subsection{Changing Layer Thickness}

Increasing the powder layer thickness between each solidification phase with the laser could help to speed up the overall time to manufacture a part. However, if the powder layer is too thick, then a melt pool with adequate depth to melt and fuse two successive layers may not be created. A thick layer of powder requires a slower scan speed or a higher laser power to achieve the same effective melt pool.

Kempen et al. evaluated the effect of changing layer thickness on hardness and density of a particular steel alloy (18Ni-300) [1]. They found that as the layer thickness increased from $0.03 \mathrm{~mm}$ to $0.06 \mathrm{~mm}$, hardness decreased as did relative density. Sun et al. used titanium (Ti-6Al-4V) powder with a custom-made selective laser melting (SLM) system [2]. They also found that the density decreased as the layer thickness increased. Deffley found that increasing layer thickness resulted in an increase in porosity, leading to a decrease in density, in the manufactured part [3]. Dingal et al. used iron powder on a custom laser sintering system and found that increasing the powder layer thickness from $0.2 \mathrm{~mm}$ to $0.4 \mathrm{~mm}$ resulted in an increase in porosity, and a reduction of density and hardness [4].

Delgado et al. assessed the impact of changing the layer thickness on two different AM systems with corresponding stainless steel powders [5]. One system produced parts with lower hardness with increasing layer thickness, while the other system did not result in a significant change in hardness with increasing layer thickness.

\subsection{Changing Scan Speed}

Scan speed, or the speed of the laser beam traveling across the powder layer melting the powder, is important for decreasing the overall build time to manufacture a LPBF part. However, if the scan speed is too high, the laser may not have sufficient time to melt the powder. Decreasing the hatch distance or increasing the laser power may improve the melting process and achieve the same energy density while allowing a faster scan speed. 
Kempen et al. found that as scan speed was increased from $120 \mathrm{~mm} / \mathrm{s}$ to $600 \mathrm{~mm} / \mathrm{s}$, hardness and the relative density of steel (18Ni-300) decreased [1]. Sun et al. found that the density of titanium alloy (Ti-6Al-4V) increased with decreasing scan speed [2]. In their comparative study of two AM systems, Delgado et al. observed that while one system resulted in reduced hardness and ultimate tensile strength (UTS) with increased scan speed, the other systems did not result in any significant difference in either hardness or UTS [5].

In their study, Vandenbroucke and Kruth optimized scan speed to minimize porosity and achieve mechanical property requirements for hardness, strength, stiffness, and ductility of titanium alloy parts made on a LPBF system [6]. Laser power and layer thickness were kept constant. For increasing scan speed from $90 \mathrm{~mm} / \mathrm{s}$ to $190 \mathrm{~mm} / \mathrm{s}$, scan tracks were not fully melted with large pores and the measured part density decreased. Qiu et al. also used a similar AM system to produce titanium-based alloy (Ti-6Al-4V) parts and changed the scan speed from $800 \mathrm{~mm} / \mathrm{s}$ to $1500 \mathrm{~mm} / \mathrm{s}$ [7]. They found that porosity decreased as scan speed increased. However, Abele et al. found that increasing scan speed from $1150 \mathrm{~mm} / \mathrm{s}$ to $1350 \mathrm{~mm} / \mathrm{s}$ resulted in increasing porosity and decreasing tensile strength of stainless steel specimens [8].

Liu et al. varied the scan speed for powders with two different particle size distributions [9]. The resulting part bulk density decreased with increasing scan speed. The UTS reached a maximum level with their range of scan speeds suggesting an optimal scan speed for their system. Gu et al. found a similar relationship where reducing scan speed from $1200 \mathrm{~mm} / \mathrm{s}$ to $600 \mathrm{~mm} / \mathrm{s}$ reduced the porosity and increased the density of stainless steel specimens [10]. Song et al. increased the scanning speed from $100 \mathrm{~mm} / \mathrm{s}$ to $300 \mathrm{~mm} / \mathrm{s}$ and found a decrease in hardness for another nickel alloy (NiCr) [11].

\subsection{Changing Hatch Distance}

Hatch distance is the length between the center of sequential laser tracks as the laser beam passes across the powder layer. Decreasing the hatch distance will increase the overlap of each laser pass and could over burn the outer edge of the laser track. Increasing the hatch distance may not allow the laser to overlap enough and result in insufficient melting of the powder. 
In their study, Vandenbroucke and Kruth optimized the hatch distance to minimize porosity, and to meet mechanical property requirements for hardness, strength, stiffness, and ductility of titanium alloy parts made on a LPBF system [6]. The laser power and layer thickness were kept constant. Increasing the hatch distance from $0.12 \mathrm{~mm}$ to $0.14 \mathrm{~mm}$ resulted in scan tracks that were not fully melted, had large pores, and decreased density. Sun et al. also used titanium alloy powder with a custom-made LPBF system while changing hatch distance [2]. As hatch distance decreased, density increased.

Abele et al. examined how energy density-related parameters influenced porosity and mechanical properties for thin walled hollow cylinders made from stainless steel [8]. They found that the hatch distance had the greatest impact on tensile strength. The scan speed had the second greatest impact, and that laser power had the least impact on the tensile strength. Increasing the hatch distance from $0.12 \mathrm{~mm}$ to $0.19 \mathrm{~mm}$ increased the porosity and decreased the tensile strength.

\subsection{Changing Laser Power}

The laser power affects the amount of energy applied to melt the powder layer and to create an effective melt pool. Reducing the laser power may result in insufficient melting of the powder, or decrease the depth of laser penetration into the powder layer to fully melt the powder and fuse successive layers together. Too much laser power can cause vaporization, which traps gas bubbles and creates porosity in the newly melted powder layers [12].

Yadroitsev et al. investigated the influence of energy density related parameters on geometrical characteristics of single tracks of melted stainless steel powder on a LPBF machine [13]. They found that the most influential parameter on geometrical characteristics of a single track was laser power (then powder layer thickness, scanning speed, and finally of least importance, the powder particle size).

$\mathrm{Gu}$ et al. decreased the laser power from $195 \mathrm{~W}$ to $70 \mathrm{~W}$ and decreased scan speed from $800 \mathrm{~mm} / \mathrm{s}$ to $287 \mathrm{~mm} / \mathrm{s}$ but maintained a constant energy density $\left(61 \mathrm{~J} / \mathrm{mm}^{3}\right)$ in their study using stainless steel powder [10]. They found that porosity increased and density decreased. Dingal et al. increased laser power for iron powder using a custom laser sintering system and found a reduction in porosity [4]. Abele et al. found that although laser power 
had the least impact to tensile strength (largest impact was hatch distance, second largest impact was scan speed), increasing laser power from $165 \mathrm{~W}$ to $180 \mathrm{~W}$ reduced porosity and increased tensile strength of stainless steel (17-4 PH) specimens [8]. Qiu et al. also found that increasing the laser power from $150 \mathrm{~W}$ to $200 \mathrm{~W}$ resulted in less porosity of titanium alloy specimens [7].

A summary of the literature search describing the effects of various LPBF process parameters related to energy density on the resulting manufactured material is given in Table 1. 
Table 1. Summary of research of various AM systems and metal powders and the results of changing layer thickness, scan speed, hatch distance, or laser power (SLS = selective laser sintering, DMLS = direct metal laser sintering, SLM = selective laser melting, SS = stainless steel, Inc $=$ increase, Dec $=$ decrease, UTS $=$ ultimate tensile strength, str $=$ strength $)$.

\begin{tabular}{|c|c|c|c|}
\hline Researcher & LPBF System & Powder & Observed Effect \\
\hline \multicolumn{4}{|c|}{ Modified parameter: Increase layer thickness $\lambda$} \\
\hline Dingal et al. (2008) [4] & Custom SLS & Iron (Atomet 86) & $\begin{array}{l}\text { Inc porosity } \nearrow \\
\text { Dec density } \searrow \\
\text { Dec hardness } \searrow\end{array}$ \\
\hline Kempen et al. (2011) [1] & $\begin{array}{l}\text { SLM (Concept Laser } \\
\text { M3) }\end{array}$ & $18 \mathrm{Ni}-300$ steel & 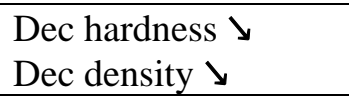 \\
\hline Deffley (2012) [3] & DMLS (EOS M270) & IN718 & Inc porosity $\nearrow$ \\
\hline Delgado et al. (2012) [5] & $\begin{array}{l}\text { SLM (Concept Laser } \\
\text { M3 Linear) }\end{array}$ & CL 20 (316L SS) & $\begin{array}{l}\text { Dec hardness } \searrow \\
\text { Dec UTS } \searrow\end{array}$ \\
\hline Delgado et al. (2012) [5] & DMLS (EOS M250) & DS H20 (SS) & Dec UTS \ \\
\hline Sun et al. (2013) [2] & SLM & Ti-6Al-4V & Dec density \ \\
\hline \multicolumn{4}{|c|}{ Modified parameter: Increase scan speed $\lambda$} \\
\hline $\begin{array}{l}\text { Vandenbroucke and Kruth } \\
\text { (2007) [6] }\end{array}$ & $\begin{array}{l}\text { SLM (Concept Laser } \\
\text { M3) }\end{array}$ & $\begin{array}{l}\text { Ti-6Al-4V/Co- } \\
\text { Cr-Mo }\end{array}$ & Dec density \} $\\
{\hline \text { Kempen et al. (2011) [1] }} &{\begin{array}{l}\text { SLM (Concept Laser } \\
\text { M3) }\end{array}} &{18 \mathrm{Ni}-300 \text { steel }} &{\begin{array}{l}\text { Dec density } \searrow \\
\text { Dec hardness } \searrow\end{array}} \\
{\hline \text { Liu et al. (2011) [9] }} &{\text { SLM (Realizer) }} &{316 \mathrm{~L}(\mathrm{SS})} &{\begin{array}{l}\text { Dec density } \searrow \\
\text { Inc UTS (peak) } \nearrow\end{array}} \\
{\hline \text { Delgado et al. (2012) [5] }} &{\begin{array}{l}\text { SLM (Concept Laser } \\
\text { M3 Linear) }\end{array}} &{\text { CL } 20 \text { (316L SS) }} &{\begin{array}{l}\text { Dec hardness } \searrow \\
\text { Dec UTS } \searrow\end{array}} \\
{\hline \text { Delgado et al. (2012) [5] }} &{\text { DMLS (EOS M250) }} &{\text { DS H20 (SS) }} &{\begin{array}{l}\text { No effect on hardness } \\
\text { or UTS }\end{array}} \\
{\hline \text { Gu et al. (2013) [10] }} &{\text { DMLS (EOS M270) }} &{17-4 \mathrm{PH}(\mathrm{SS})} &{\begin{array}{l}\text { Dec density } \searrow \\
\text { Inc porosity } \nearrow\end{array}} \\
{\hline \text { Qiu et al. (2013) [7] }} &{\begin{array}{l}\text { SLM (Concept Laser } \\
\text { M2) }\end{array}} &{\text { Ti-6Al-4V }} &{\text { Dec porosity \ }} \\
{\hline \text { Sun et al. (2013) [2] }} &{\text { SLM }} &{\text { Ti-6Al-4V }} &{\text { Dec density \} } \\
{\hline \text { Song et al. (2014) [11] }} &{\text { SLM (Realizer) }} &{\mathrm{Ni} 20 \mathrm{Cr}} &{\text { Dec hardness \ }} \\
{\hline \text { Abele et al. (2015) [8] }} &{\text { DMLS (EOS M270) }} &{17-4 \mathrm{PH}(\mathrm{SS})} &{\begin{array}{l}\text { Inc porosity } \nearrow \\
\text { Dec UTS } \searrow\end{array}} \\
{\hline \multicolumn{4}{|c|}{\text { Modified parameter: Increase hatch distance } \nearrow}\text { Modified parameter: Increase hatch distance } \nearrow} \\
{\hline \begin{array}{l}\text { Vandenbroucke and Kruth } \\
\text { (2007) [6] }\end{array}} &{\begin{array}{l}\text { SLM (Concept Laser } \\
\text { M3) }\end{array}} &{\begin{array}{l}\text { Ti-6Al-4V/Co- } \\
\text { Cr-Mo }\end{array}} &{\text { Dec density \} } \\
{\hline \text { Sun et al. (2013) [2] }} &{\text { SLM }} &{\text { Ti-6Al-4V }} &{\text { Dec density } \searrow} \\
{\hline \text { Abele et al. (2015) [8] }} &{\text { DMLS (EOS M270) }} &{17-4 \mathrm{PH}(\mathrm{SS})} &{\begin{array}{l}\text { Inc porosity } \nearrow \\
\text { Dec tensile str } \searrow\end{array}} \\
{\hline \multicolumn{4}{|c|}{\text { Modified parameter: Increase laser power } \nearrow}\text { Modified parameter: Increase laser power } \nearrow} \\
{\hline \text { Dingal et al. (2008) [4] }} &{\text { Custom SLS }} &{\text { Iron (Atomet 86) }} &{\text { Dec porosity \} } \\
{\hline \text { Gu et al. (2013) [10] }} &{\text { DMLS (EOS M270) }} &{17-4 \mathrm{PH}(\mathrm{SS})} &{\begin{array}{l}\text { Dec porosity } \searrow \\
\text { Inc density } \nearrow\end{array}} \\
\hline\end{array}$
\end{tabular}




\begin{tabular}{|c|c|c|c|}
\hline Qiu et al. (2013) [7] & $\begin{array}{l}\text { SLM (Concept Laser } \\
\text { M2) }\end{array}$ & Ti-6Al-4V & Dec porosity $\searrow$ \\
\hline Abele et al. (2015) [8] & DMLS (EOS M270) & 17-4 PH (SS) & $\begin{array}{l}\text { Dec porosity } \searrow \\
\text { Inc tensile str } \nearrow\end{array}$ \\
\hline \multicolumn{4}{|c|}{ Modified parameter: Changed multiple parameters } \\
\hline Yadroitsev (2012) [13] & SLM (Phenix PM100) & $904 \mathrm{~L}(\mathrm{SS})$ & $\begin{array}{l}\text { Laser power is the } \\
\text { most influential } \\
\text { parameter for single } \\
\text { track geometry }\end{array}$ \\
\hline
\end{tabular}

\section{Experimental Method}

Three sets of blocks were manufactured using IN625 metal powder (nitrogen gas atomized) on a LPBF machine (EOS M270) to understand the relationship between LPBF process parameters and the hardness and the density of the manufactured IN625 material. The first build (Build \#2-16) of 17 blocks used a wide range of process parameters (16 different parameter sets) to investigate the boundaries of 'buildable' parameter combinations (Figure 1). A second set of 17 blocks was fabricated (Build \#3-16) with slightly different parameter sets (again 16 sets in total) after eliminating some parameter combinations resulting in unsuccessful builds in the first group (Figure 2). Finally, a third set of 37 blocks was fabricated (Build \#17-16) using a smaller range of parameters (9 different parameter sets) to ensure acceptable builds while generating the widest possible range of mechanical behavior (Figure 3). In the third build, four replicate blocks were fabricated for each of the nine parameter sets (see Appendix A, B, and C for the build drawing and build report for each build). One block at the center location of each build plate was labeled as "dummy" and was used as a sacrificial block to adjust the hardness measuring instrument prior to measuring the blocks of interest. 


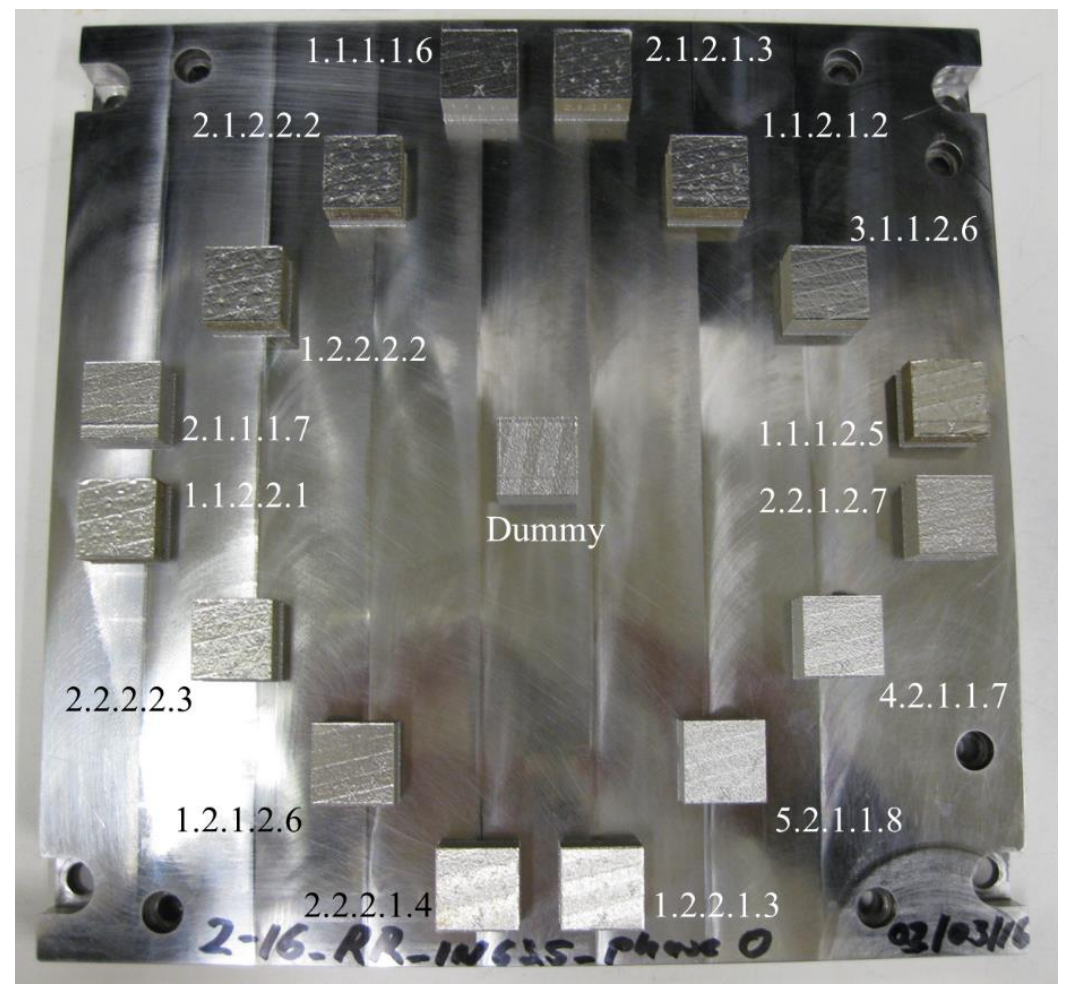

Figure 1. Layout of the first build (Build \#2-16) (Block identification (ID) numbers are also shown).

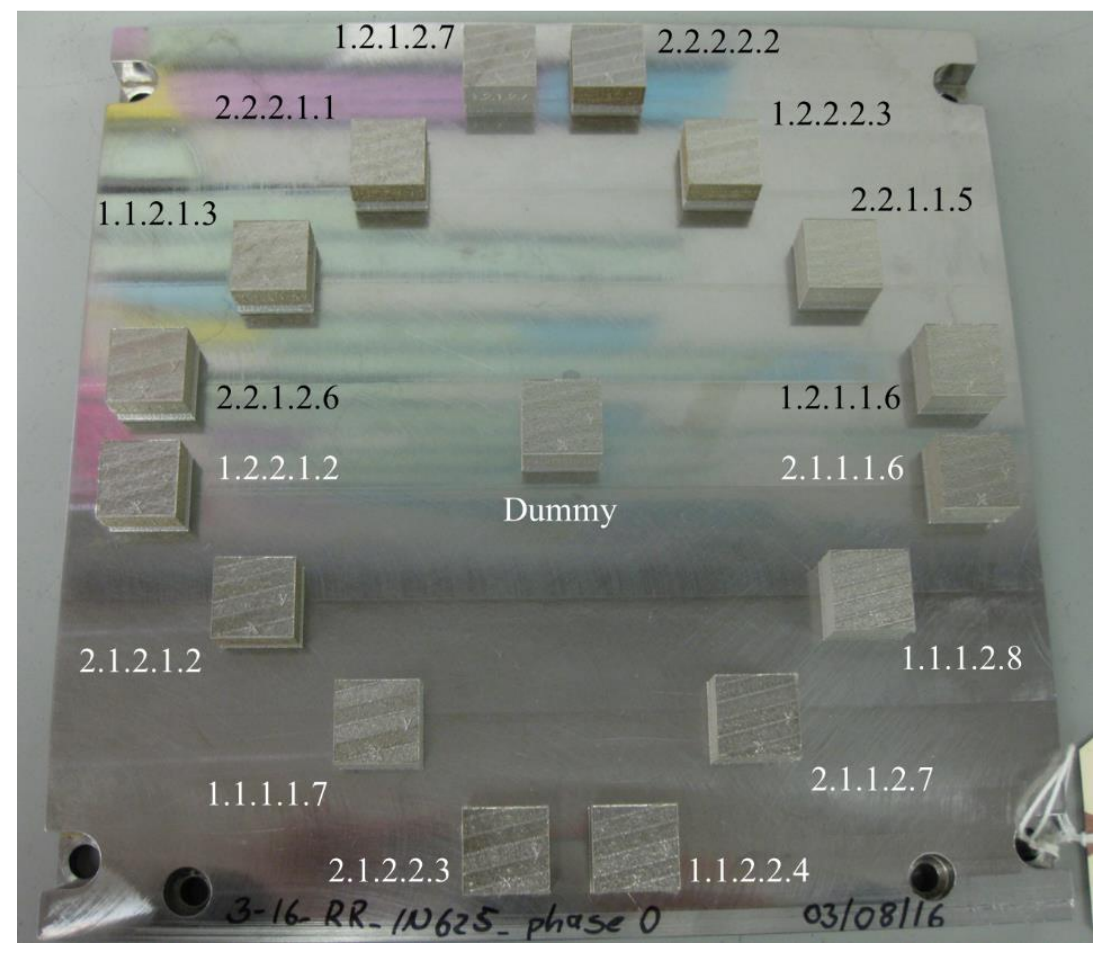

Figure 2. Layout of the second build (Build \#3-16) (Block identification (ID) numbers are also shown). 


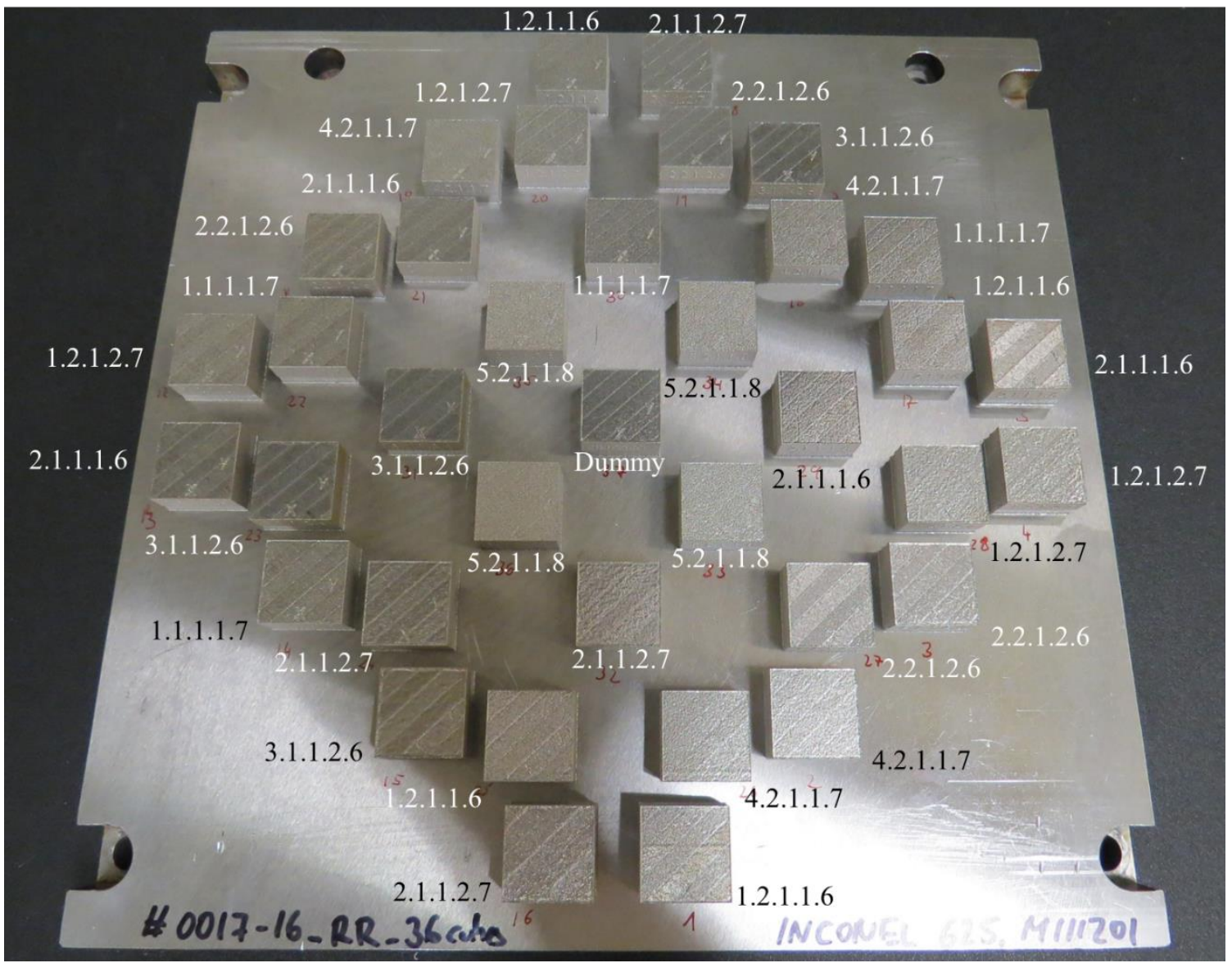

Figure 3. Layout of the third build (Build \#17-16) (Block identification (ID) numbers are also shown).

Different combinations of process parameters were used for each block for the three builds (Table 2). The default parameters were chosen based on the machine vendor's recommendations (recipes) for IN625. In addition to the default parameters, variations made to the four process parameters: powder layer thickness, hatch distance, scan speed, and laser power. Each combination of process parameters resulted in distinct build volume rates and energy densities. 
Table 2. Process parameters for each of the three builds. Volume rate and energy density were calculated based on these parameters. See Appendices A, B, and C for a complete list of parameters for each build.

\begin{tabular}{|l|c|c|c|}
\hline \multicolumn{1}{|c|}{ Process parameters } & Build \#2-16 & Build \#3-16 & Build \#17-16 \\
\hline Hatch distance, $h(\mathrm{~mm})$ & 0.08 & 0.08 & 0.08 \\
& 0.1 & 0.1 & 0.1 \\
\hline Layer thickness, $t(\mathrm{~mm})$ & 0.02 & 0.02 & 0.02 \\
& 0.04 & 0.04 & \\
\hline Laser power, $P(\mathrm{~W})$ & 156 & 156 & 156 \\
& 195 & 195 & 195 \\
\hline Scan speed, $v(\mathrm{~mm} / \mathrm{s})$ & 320 & 320 & \\
& 400 & 400 & \\
& 500 & 500 & \\
& 625 & 625 & \\
& 640 & 640 & 800 \\
& 800 & 800 & 1000 \\
& 1000 & 1000 & 1250 \\
\hline Volume Rate $=h \cdot t \cdot v\left(\mathrm{~mm}^{3} / \mathrm{s}\right)$ & 1250 & 1250 & \\
& 1.0 & & 1.3 \\
& 1.3 & 1.3 & 1.6 \\
& 1.6 & 1.6 & 2.0 \\
& 2.0 & 2.0 & 2.5 \\
\hline Energy Density $=P /(h \cdot t \cdot v)$ & 2.5 & & 62.4 \\
$\left(\mathrm{~J} / \mathrm{mm}^{3}\right)$ & 62.4 & & 97.0 \\
& 78.0 & & 121.9 \\
& 97.5 & 97.5 & 152.3 \\
& 121.9 & 121.9 & \\
& 152.3 & & \\
& 190.4 & & \\
\hline
\end{tabular}

After the manufacturing process was completed, the build plates were heat treated, as recommended by the machine vendor, at $870{ }^{\circ} \mathrm{C}$ for one hour with subsequent air cooling. The blocks were first separated from the build plate by wire electrical discharge machining (EDM) and then machined to a final dimension of $20 \mathrm{~mm}$ (length) x $20 \mathrm{~mm}$ (width) $\mathrm{x} 8 \mathrm{~mm}$ (height). Due to the variations in the EDM process, some blocks were thinner than $8 \mathrm{~mm}$ (Appendix D).

Hardness measurements were chosen to characterize the mechanical properties of the blocks because they are relatively fast measurements requiring small specimens, many of 
which can be built on a single build platform as opposed to manufacturing tensile bars that require additional material, build time, build space, and post machining.

Rockwell hardness scale A (HRA) and C (HRC) were used for this study. Rockwell hardness testing probes a greater volume of material and was preferred over microindentation techniques, such as Knoop or Vickers hardness testing, which evaluate the material only at a thin layer of the surface. Both HRA and HRC use the same spheroconical diamond indenter, with HRA testing performed using a force of $100 \mathrm{kgf}(980.7 \mathrm{~N})$, while the HRC uses $150 \mathrm{kgf}$ $(1471 \mathrm{~N})$. Eight indents were made on one surface of each of the blocks for HRC, and four indents were made on the same surface for HRA. Upon completion of the hardness measurements, a subset of seven blocks was selected to represent a wide range of process parameters for density measurements, which were performed with a Helium gas pycnometer (AccuPyc II 1340 V1.05). Smaller specimens were cut out of these blocks with EDM to fit into the pycnometer. Ten density measurements were made per specimen to determine the average density.

The blocks were then sectioned and imaged using bright-field microscopy in the aspolished and etched conditions (Appendix E).

\section{Results / Discussion}

\subsection{Hardness}

Table 3 and Table 4 show the hardness results for the first two builds (Build \#2-16 and Build \#3-16) including the parameter settings for each block. Each block included a fivedigit identification number where each digit represented a different parameter setting (energy density, hatch distance, layer thickness, laser power, and scan speed). 
Table 3. Hardness results and parameter settings for each of the blocks (without the "dummy") from Build \#2-16. Blocks with gray rows had high standard deviations (see Figure 4) or were observed to have issues during manufacturing as shown in Figures 5A and 5B.

\begin{tabular}{|c|c|c|c|c|c|c|c|c|}
\hline $\begin{array}{c}\text { BLOCK \# } \\
\text { (BLOCK ID) }\end{array}$ & $\begin{array}{l}\text { HATCH } \\
\text { DIST } \\
(\mathrm{mm})\end{array}$ & $\begin{array}{c}\text { LAYER } \\
\text { THICKNESS } \\
(\mathrm{mm})\end{array}$ & $\begin{array}{c}\text { LASER } \\
\text { POWER } \\
\text { (W) }\end{array}$ & $\begin{array}{l}\text { SCAN } \\
\text { SPEED } \\
(\mathrm{mm} / \mathrm{s})\end{array}$ & $\begin{array}{c}\text { VOL } \\
\text { RATE } \\
\left(\mathrm{mm}^{3} / \mathrm{s}\right)\end{array}$ & $\begin{array}{l}\text { ENERGY } \\
\text { DENSITY } \\
\left(\mathrm{J} / \mathrm{mm}^{3}\right)\end{array}$ & $\begin{array}{l}\text { HRC AVG } \\
\text { (STD DEV) }\end{array}$ & $\begin{array}{l}\text { HRA AVG } \\
\text { (STD DEV) }\end{array}$ \\
\hline $\begin{array}{c}1 \\
(2.2 .2 .1 .4)\end{array}$ & 0.1 & 0.04 & 156 & 625 & 2.5 & 62.4 & $\begin{array}{l}33.4 \\
(0.2)\end{array}$ & $\begin{array}{l}67.6 \\
(0.3)\end{array}$ \\
\hline $\begin{array}{c}2 \\
(1.2 .2 .1 .3)\end{array}$ & 0.1 & 0.04 & 156 & 500 & 2.0 & 78.0 & $\begin{array}{l}33.9 \\
(0.3)\end{array}$ & $\begin{array}{l}67.5 \\
(0.4)\end{array}$ \\
\hline $\begin{array}{c}3 \\
(1.2 .1 .2 .6)\end{array}$ & 0.1 & 0.02 & 195 & 800 & 1.6 & 121.9 & $\begin{array}{l}35.5 \\
(0.2)\end{array}$ & $\begin{array}{l}68.7 \\
(0.2)\end{array}$ \\
\hline $\begin{array}{c}4 \\
(5.2 .1 .1 .8)\end{array}$ & 0.1 & 0.02 & 156 & 1250 & 2.5 & 62.4 & $\begin{array}{l}33.8 \\
(0.2)\end{array}$ & $\begin{array}{l}67.7 \\
(0.2)\end{array}$ \\
\hline $\begin{array}{c}5 \\
(1.1 .2 .2 .1)\end{array}$ & 0.08 & 0.04 & 195 & 320 & 1.0 & 190.4 & $\begin{array}{l}33.6 \\
(0.8)\end{array}$ & $\begin{array}{l}67.9 \\
(0.1)\end{array}$ \\
\hline $\begin{array}{c}6 \\
(2.1 .2 .1 .3)\end{array}$ & 0.08 & 0.04 & 156 & 500 & 1.6 & 97.5 & $\begin{array}{l}33.0 \\
(1.7)\end{array}$ & $\begin{array}{l}61.5 \\
(9.2)\end{array}$ \\
\hline $\begin{array}{c}7 \\
(1.2 .2 .2 .2)\end{array}$ & 0.1 & 0.04 & 195 & 400 & 1.6 & 121.9 & $\begin{array}{l}32.5 \\
(0.4)\end{array}$ & $\begin{array}{l}67.2 \\
(0.4)\end{array}$ \\
\hline $\begin{array}{c}8 \\
(2.2 .1 .2 .7)\end{array}$ & 0.1 & 0.02 & 195 & 1000 & 2.0 & 97.5 & $\begin{array}{l}35.4 \\
(0.3)\end{array}$ & $\begin{array}{l}68.4 \\
(0.1)\end{array}$ \\
\hline $\begin{array}{c}9 \\
(4.2 .1 .1 .7)\end{array}$ & 0.1 & 0.02 & 156 & 1000 & 2.0 & 78.0 & $\begin{array}{l}34.8 \\
(0.3)\end{array}$ & $\begin{array}{l}68.1 \\
(0.1)\end{array}$ \\
\hline $\begin{array}{c}10 \\
(1.1 .1 .1 .6)\end{array}$ & 0.08 & 0.02 & 156 & 800 & 1.3 & 121.9 & $\begin{array}{l}36.0 \\
(0.2)\end{array}$ & $\begin{array}{l}68.8 \\
(0.2)\end{array}$ \\
\hline $\begin{array}{c}11 \\
(1.1 .2 .1 .2)\end{array}$ & 0.08 & 0.04 & 156 & 400 & 1.3 & 121.9 & $\begin{array}{l}32.6 \\
(2.8)\end{array}$ & $\begin{array}{l}66.8 \\
(0.5)\end{array}$ \\
\hline
\end{tabular}




\begin{tabular}{|c|c|c|c|c|c|c|c|c|}
\hline $\begin{array}{c}12 \\
(3.1 .1 .2 .6)\end{array}$ & 0.08 & 0.02 & 195 & 800 & 1.3 & 152.3 & $\begin{array}{l}36.2 \\
(0.2)\end{array}$ & $\begin{array}{l}68.9 \\
(0.3)\end{array}$ \\
\hline $\begin{array}{c}13 \\
(1.1 .1 .2 .5)\end{array}$ & 0.08 & 0.02 & 195 & 640 & 1.0 & 190.4 & $\begin{array}{l}35.8 \\
(0.3)\end{array}$ & $\begin{array}{l}68.7 \\
(0.1)\end{array}$ \\
\hline $\begin{array}{c}14 \\
(2.2 .2 .2 .3)\end{array}$ & 0.1 & 0.04 & 195 & 500 & 2.0 & 97.5 & $\begin{array}{l}33.4 \\
(0.3)\end{array}$ & $\begin{array}{l}67.4 \\
(0.4)\end{array}$ \\
\hline $\begin{array}{c}15 \\
(2.1 .2 .2 .2)\end{array}$ & 0.08 & 0.04 & 195 & 400 & 1.3 & 152.3 & $\begin{array}{l}32.5 \\
(0.5)\end{array}$ & $\begin{array}{l}65.8 \\
(1.4)\end{array}$ \\
\hline $\begin{array}{c}16 \\
(2.1 .1 .1 .7)\end{array}$ & 0.08 & 0.02 & 156 & 1000 & 1.6 & 97.5 & $\begin{array}{l}35.4 \\
(0.2)\end{array}$ & $\begin{array}{l}68.4 \\
(0.3)\end{array}$ \\
\hline
\end{tabular}

Table 4. Hardness results and parameter settings for each of the blocks (without the "dummy") from Build \#3-16. Blocks with gray rows had high standard deviations (see Figure 4) or were observed to have issues during manufacturing as shown in Figures 5A and 5B.

\begin{tabular}{|c|c|c|c|c|c|c|c|c|}
\hline $\begin{array}{c}\text { BLOCK \# } \\
\text { (BLOCK ID) }\end{array}$ & $\begin{array}{c}\text { HATCH } \\
\text { DIST } \\
(\mathrm{mm})\end{array}$ & $\begin{array}{c}\text { LAYER } \\
\text { THICKNESS } \\
(\mathrm{mm})\end{array}$ & $\begin{array}{l}\text { LASER } \\
\text { POWER } \\
\text { (W) }\end{array}$ & $\begin{array}{l}\text { SCAN } \\
\text { SPEED } \\
(\mathrm{mm} / \mathrm{s})\end{array}$ & $\begin{array}{c}\text { VOL } \\
\text { RATE } \\
\left(\mathrm{mm}^{3} / \mathrm{s}\right)\end{array}$ & $\begin{array}{l}\text { ENERGY } \\
\text { DENSITY } \\
\left(\mathrm{J} / \mathrm{mm}^{3}\right)\end{array}$ & $\begin{array}{l}\text { HRC AVG } \\
\text { (STD DEV) }\end{array}$ & $\begin{array}{l}\text { HRA AVG } \\
\text { (STD DEV) }\end{array}$ \\
\hline $\begin{array}{c}17 \\
(1.1 .1 .1 .7)\end{array}$ & 0.08 & 0.02 & 156 & 1000 & 1.6 & 97.5 & $\begin{array}{l}35.9 \\
(0.3)\end{array}$ & $\begin{array}{l}68.5 \\
(0.1)\end{array}$ \\
\hline $\begin{array}{c}18 \\
(1.1 .1 .2 .8)\end{array}$ & 0.08 & 0.02 & 195 & 1250 & 2.0 & 97.5 & $\begin{array}{l}35.7 \\
(0.1)\end{array}$ & $\begin{array}{l}68.8 \\
(0.2)\end{array}$ \\
\hline $\begin{array}{c}19 \\
(1.1 .2 .1 .3)\end{array}$ & 0.08 & 0.04 & 156 & 500 & 1.6 & 97.5 & $\begin{array}{l}31.8 \\
(2.6)\end{array}$ & $\begin{array}{l}68.4 \\
(2.2)\end{array}$ \\
\hline $\begin{array}{c}20 \\
(1.1 .2 .2 .4)\end{array}$ & 0.08 & 0.04 & 195 & 625 & 2.0 & 97.5 & $\begin{array}{l}34.0 \\
(0.5)\end{array}$ & $\begin{array}{l}67.9 \\
(0.4)\end{array}$ \\
\hline $\begin{array}{c}21 \\
(1.2 .1 .1 .6)\end{array}$ & 0.1 & 0.02 & 156 & 800 & 1.6 & 97.5 & $\begin{array}{l}35.8 \\
(0.4)\end{array}$ & $\begin{array}{l}68.5 \\
(0.2)\end{array}$ \\
\hline $\begin{array}{c}22 \\
(1.2 .1 .2 .7)\end{array}$ & 0.1 & 0.02 & 195 & 1000 & 2.0 & 97.5 & $\begin{array}{l}35.1 \\
(0.3)\end{array}$ & $\begin{array}{l}68.2 \\
(0.1)\end{array}$ \\
\hline
\end{tabular}




\begin{tabular}{|c|c|c|c|c|c|c|c|c|}
\hline $\begin{array}{c}23 \\
(1.2 .2 .1 .2)\end{array}$ & 0.1 & 0.04 & 156 & 400 & 1.6 & 97.5 & $\begin{array}{l}33.6 \\
(2.4)\end{array}$ & $\begin{array}{l}67.9 \\
(0.2)\end{array}$ \\
\hline $\begin{array}{c}24 \\
(1.2 .2 .2 .3)\end{array}$ & 0.1 & 0.04 & 195 & 500 & 2.0 & 97.5 & $\begin{array}{l}33.8 \\
(0.5)\end{array}$ & $\begin{array}{l}67.9 \\
(0.2)\end{array}$ \\
\hline $\begin{array}{c}25 \\
(2.1 .1 .1 .6)\end{array}$ & 0.08 & 0.02 & 156 & 800 & 1.3 & 121.9 & $\begin{array}{l}36.3 \\
(0.2)\end{array}$ & $\begin{array}{l}68.8 \\
(0.3)\end{array}$ \\
\hline $\begin{array}{c}26 \\
(2.1 .1 .2 .7)\end{array}$ & 0.08 & 0.02 & 195 & 1000 & 1.6 & 121.9 & $\begin{array}{l}36.1 \\
(0.3)\end{array}$ & $\begin{array}{l}68.8 \\
(0.2)\end{array}$ \\
\hline $\begin{array}{c}27 \\
(2.1 .2 .1 .2)\end{array}$ & 0.08 & 0.04 & 156 & 400 & 1.3 & 121.9 & $\begin{array}{l}32.7 \\
(2.6)\end{array}$ & $\begin{array}{l}69.3 \\
(1.6)\end{array}$ \\
\hline $\begin{array}{c}28 \\
(2.1 .2 .2 .3)\end{array}$ & 0.08 & 0.04 & 195 & 500 & 1.6 & 121.9 & $\begin{array}{l}34.3 \\
(0.3)\end{array}$ & $\begin{array}{l}67.8 \\
(0.3)\end{array}$ \\
\hline $\begin{array}{c}29 \\
(2.2 .1 .1 .5)\end{array}$ & 0.1 & 0.02 & 156 & 640 & 1.3 & 121.9 & $\begin{array}{l}36.0 \\
(0.3)\end{array}$ & $\begin{array}{l}68.8 \\
(0.3)\end{array}$ \\
\hline $\begin{array}{c}30 \\
(2.2 .1 .2 .6)\end{array}$ & 0.1 & 0.02 & 195 & 800 & 1.6 & 121.9 & $\begin{array}{l}36.4 \\
(0.1)\end{array}$ & $\begin{array}{l}68.8 \\
(0.2)\end{array}$ \\
\hline $\begin{array}{c}31 \\
(2.2 .2 .1 .1)\end{array}$ & 0.1 & 0.04 & 156 & 320 & 1.3 & 121.9 & $\begin{array}{l}32.8 \\
(1.9)\end{array}$ & $\begin{array}{l}67.3 \\
(0.1)\end{array}$ \\
\hline $\begin{array}{c}32 \\
(2.2 .2 .2 .2)\end{array}$ & 0.1 & 0.04 & 195 & 400 & 1.6 & 121.9 & $\begin{array}{l}33.7 \\
(0.5)\end{array}$ & $\begin{array}{l}67.6 \\
(0.4)\end{array}$ \\
\hline
\end{tabular}

Figure 4 shows the HRC and HRA results of all 32 blocks from both Build \#2-16 and Build \#3-16. Each solid circle in Figure 4A represents the average of the eight HRC indents on the top surface of each block, and each solid circle in Figure 4B represents the average of the four HRA indents. The error bars represent \pm one standard deviation. Empty circles represent the individual measurements. Several of the blocks had large variations in the hardness values, which may be due to porosity within the block resulting from either the nonuniform spread powder layer or the vaporization caused during the process (key holing) with high energy densities. The blocks with a large variation in HRC also had a large variation in 
HRA. This suggests that the observed variation was associated with the material under test, not the measurement process itself. The porosity was apparently distributed throughout the block rather than localized since the HRC and HRA measurements were taken from different locations across the block surface.

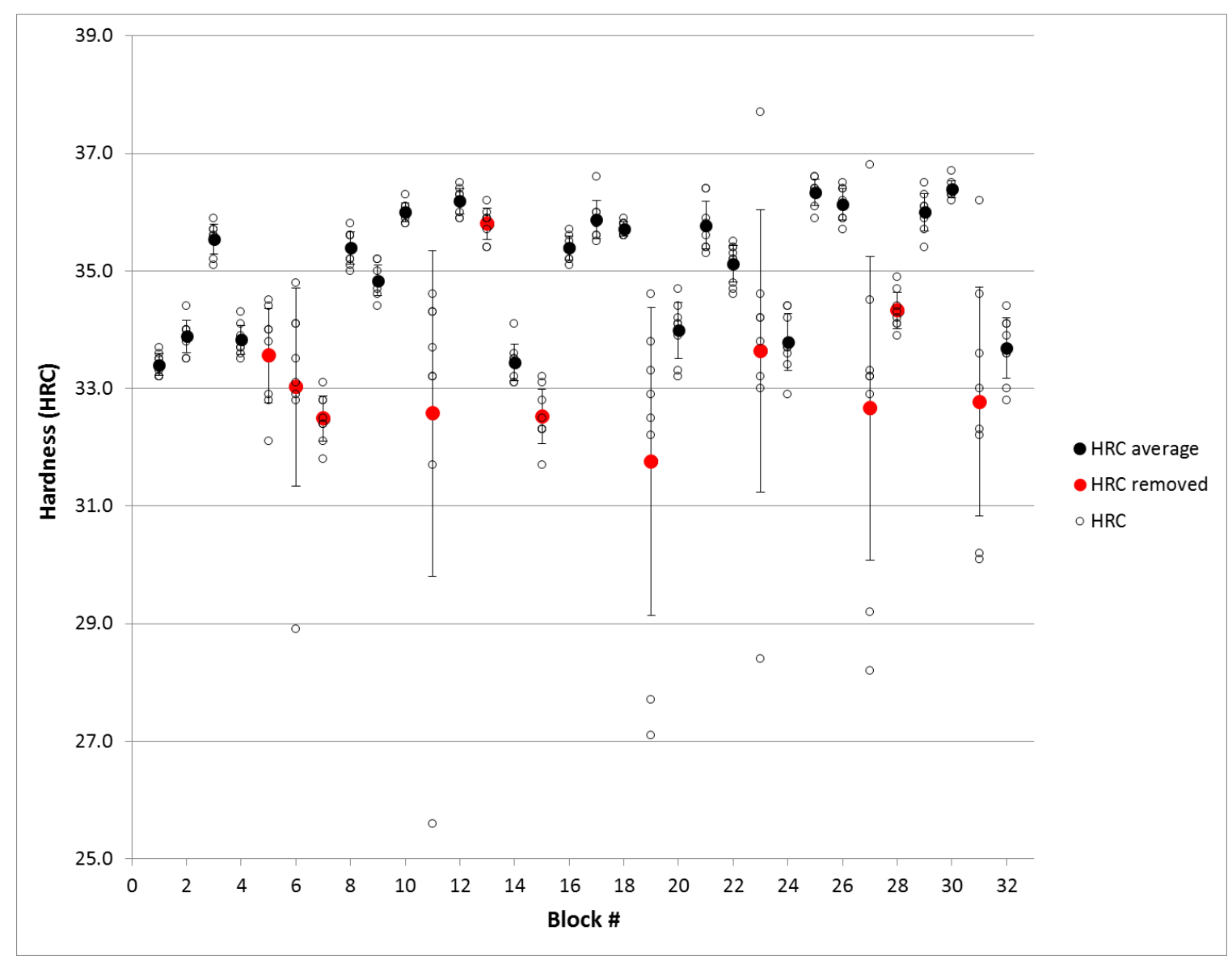

A 


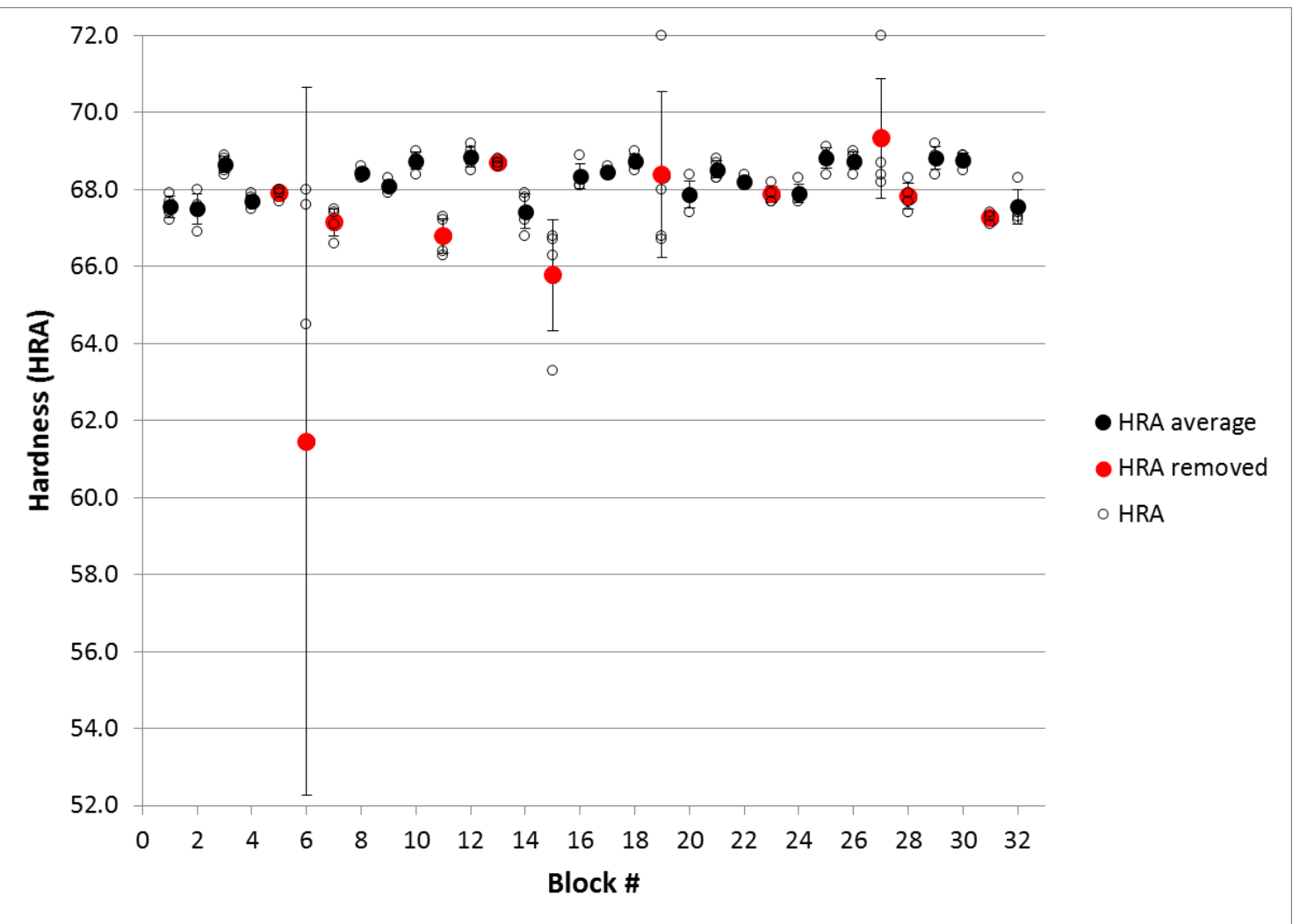

B

Figure 4A and 4B. HRC and HRA hardness values for all 32 blocks from Build \#2-16 and Build \#3-16. The blocks for both plots are listed in the same order along the $x$ axis. Red circles indicate blocks that had high standard deviations or were observed to have issues during manufacturing as shown in Figures 5A and 5B. These blocks were also in gray in Tables 3 and 4 .

Visual observations were made during the manufacturing process of Build \#2-16 and Build \#3-16 (Figure 5, A and B). During the manufacturing process, the surfaces of some block layers appeared rough, both along the block perimeter and within the block's interior. This may have resulted in unevenly spread powder across the block surface. During the laser melting step, surfaces with uniform powder layers continued to build normally, while the rough surfaces promoted more uneven surfaces that produced gaps in the spread powder. 


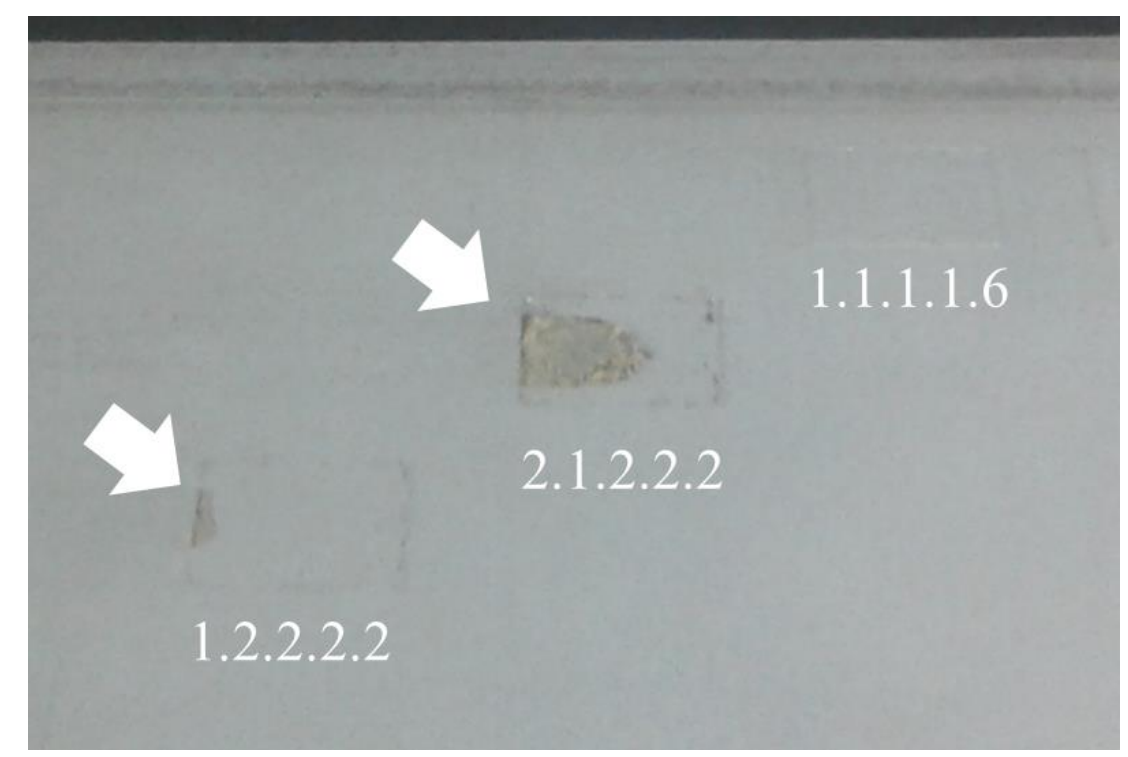

A

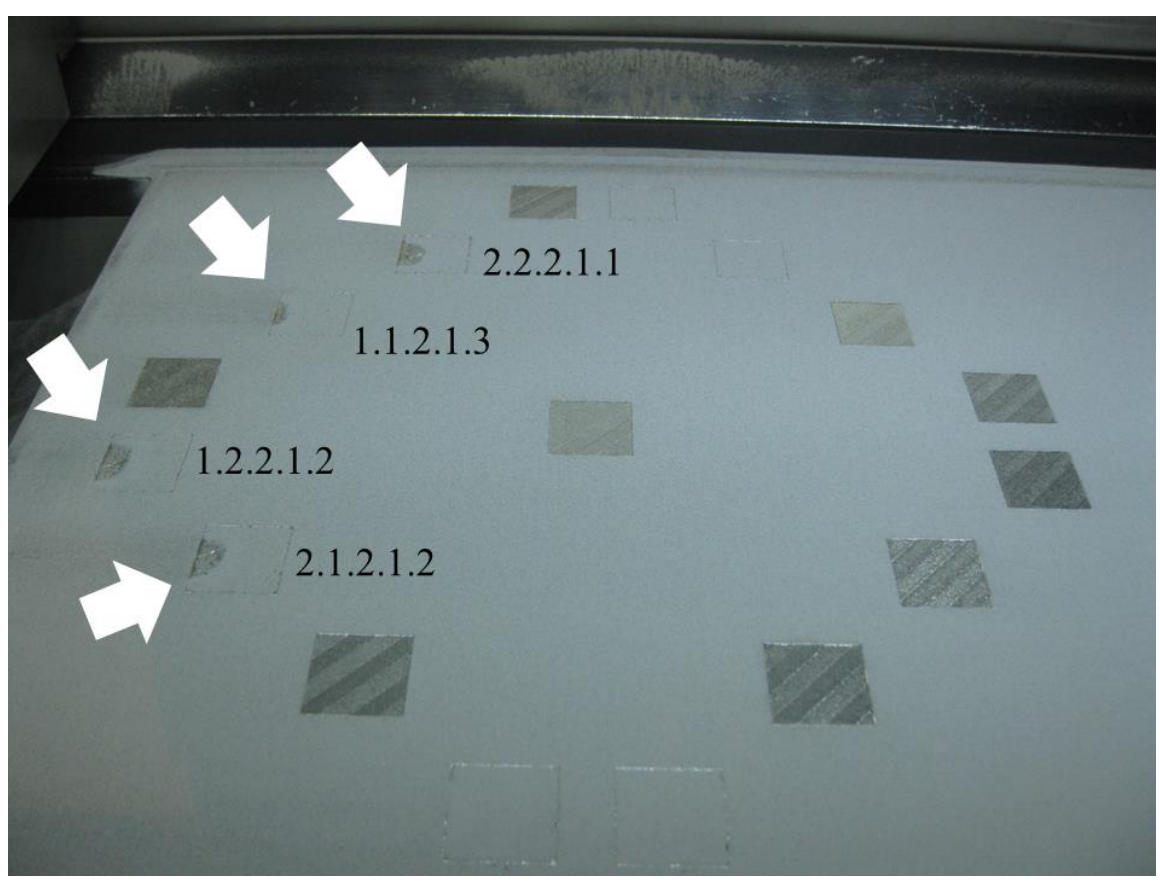

$\mathrm{B}$

Figure 5A and 5B. Manufacturing issues were noted during the build process because of incomplete coverage of the powder layer for blocks with uneven surfaces. In Figure 5A, two blocks are identified from Build \#2-16 that show incomplete powder layer coverage. The shiny metallic surface (see arrow) is the previous layer of solidified powder that was not covered by a fresh layer of spread powder due to the rough surfaces within the block's interior. In Figure 5B, four blocks are identified from Build \#3-16 with incomplete powder layer coverage (see arrows). 
Eleven blocks were identified (gray rows in Tables 3 and 4, and red markers in Figure 4A and 4B) to have either non-uniformly spread powder across the surface of the block during manufacturing (Figure 5), or had large variations of the measured hardness. Based on the observations during the builds and the hardness results, these eleven blocks were removed from the data set and hardness plotted again (Figure 6A and 6B). The HRC data were in two groups, an upper group with average hardness of approximately $36 \mathrm{HRC}$, and a lower group with an average hardness of approximately 34 HRC. Similarly, HRA hardness measurements demonstrated the same pattern as the HRC measurements. Although both reflected the same trend, the HRC scale results demonstrated a higher sensitivity to the processing parameters, as evidenced by obtaining twice the range in hardness values for the HRC hardness scale when compared to the values obtained using the HRA hardness scale, while the reported values for both scales expressed using the same number of significant digits. In addition, the higher volume of material affected by testing using the HRC hardness scale (due to the higher force used) may reduce the effect of localized imperfections on the results obtained. 


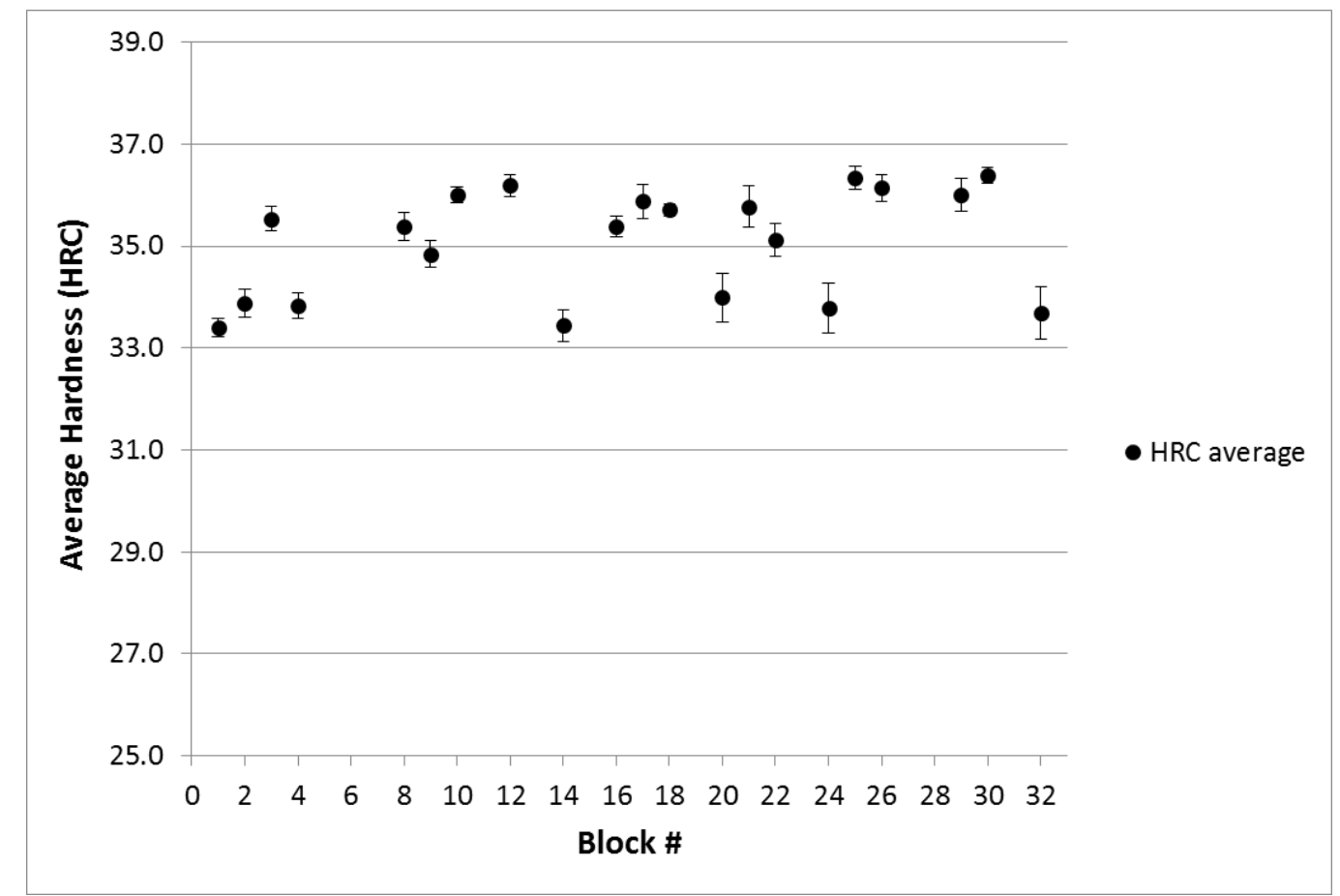

A

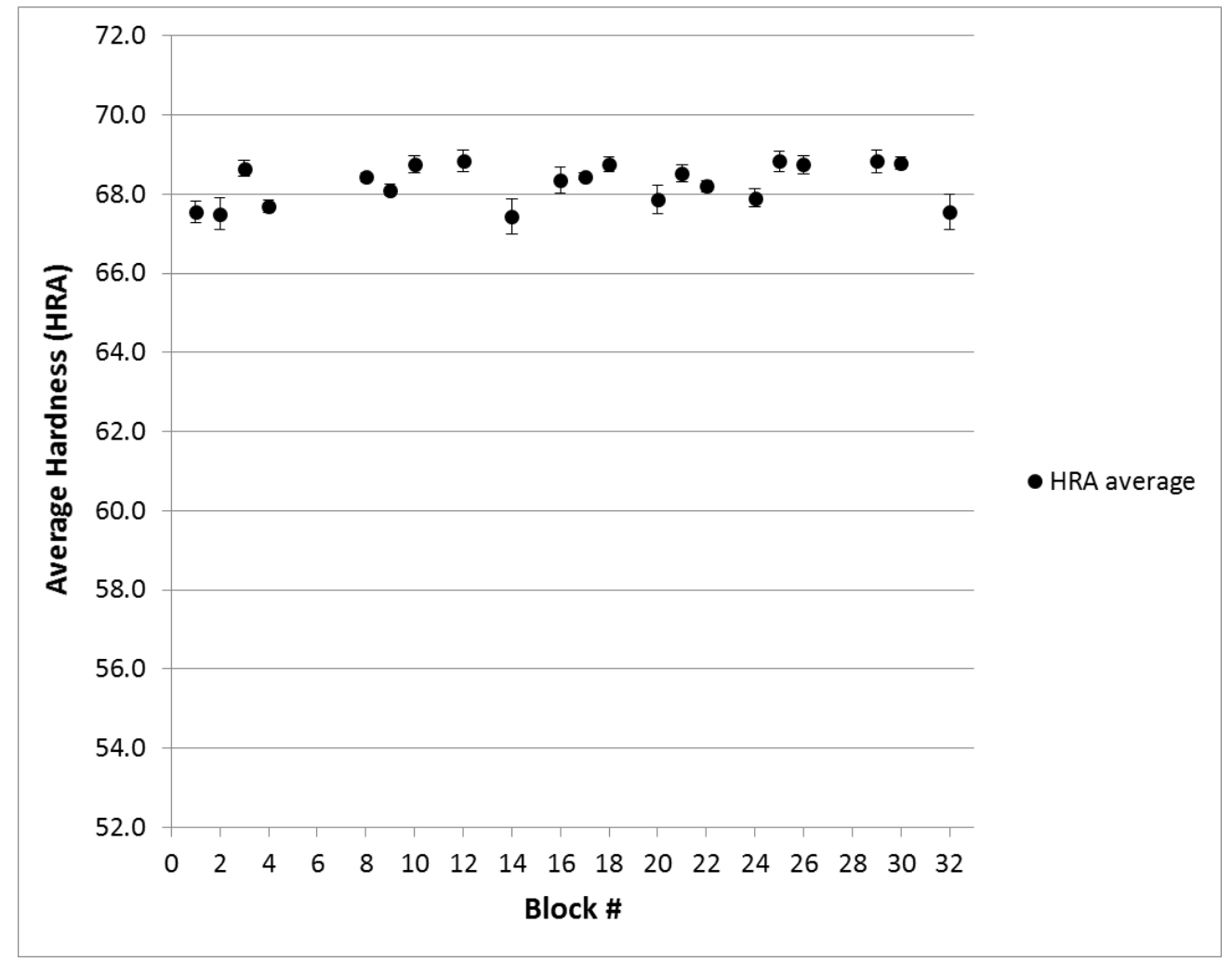

B

Figure 6A and 6B. HRC and HRA hardness values after eleven blocks with large variations and issues during manufacturing were removed from Build \#2-16 and Build \#3-16. 
The hardness results from Build \#2-16 and Build \#3-16 provided the basis for determining the process parameter settings to use for further study. For the follow-up study, nine parameter sets were chosen that provided a sufficient range of energy density values and had previously manufactured blocks with consistent hardness values. The layer thickness was held constant at $20 \mu \mathrm{m}$ because the blocks in the previous builds with a layer thickness of $40 \mu \mathrm{m}$ had a higher probability of manufacturing defects when used in combination with changes to other settings. The process parameter settings were varied by $20 \%$ either individually or in combination to achieve a range of five different energy densities (Table 5). For statistical robustness, four blocks were manufactured for each of the nine parameter sets. No issues, such as non-uniform powder spreading, were observed during the manufacturing of these blocks.

After the manufacturing process was completed, the build plate was heat treated at $870{ }^{\circ} \mathrm{C}$ for one hour with subsequent air cooling, and the blocks were removed from the build plate. Only the HRC scale was used when measuring the hardness of the blocks of Build \#17-16, allowing for a higher number of indents. In this case, the average HRC value for each block was calculated based on 11 indents made on the top surface of the block (Table 6). It is noted that the hardness values of the blocks from this build are generally lower than that of the previous builds. It is suspected that this difference is due to the small variations in the heat treatment procedures. However, since the effect of heat treatment was beyond the scope of this study, this discrepancy was not investigated. Nevertheless, Build \#17-16 provides all the necessary data to investigate the effects of process parameters on the hardness of the resulting blocks. 
Table 5. The nine process parameter sets chosen for Build \#17-16.

\begin{tabular}{|c|c|c|c|c|c|c|}
\hline BLOCK ID & $\begin{array}{l}\text { ENERGY } \\
\text { DENSITY } \\
\left(\mathrm{J} / \mathrm{mm}^{3}\right) \\
\end{array}$ & $\begin{array}{c}\text { VOLUME RATE } \\
\left(\mathrm{mm}^{3} / \mathrm{s}\right)\end{array}$ & $\begin{array}{c}\text { HATCH } \\
\text { DISTANCE } \\
(\mathrm{mm}) \\
\end{array}$ & $\begin{array}{c}\text { LAYER } \\
\text { THICKNESS } \\
(\mathrm{mm}) \\
\end{array}$ & $\begin{array}{c}\text { LASER } \\
\text { POWER } \\
(W)\end{array}$ & $\begin{array}{l}\text { SCAN } \\
\text { SPEED } \\
(\mathrm{mm} / \mathrm{s}) \\
\end{array}$ \\
\hline 2.2.1.2.6 & 121.9 & 1.6 & 0.1 & 0.02 & 195 & 800 \\
\hline 1.2.1.2.7 & 97.5 & 2.0 & 0.1 & 0.02 & 195 & 1000 \\
\hline 1.2.1.1.6 & 97.5 & 1.6 & 0.1 & 0.02 & 156 & 800 \\
\hline 3.1.1.2.6 & 152.3 & 1.3 & 0.08 & 0.02 & 195 & 800 \\
\hline 4.2.1.1.7 & 78.0 & 2.0 & 0.1 & 0.02 & 156 & 1000 \\
\hline 2.1.1.1.6 & 121.9 & 1.3 & 0.08 & 0.02 & 156 & 800 \\
\hline 2.1.1.2.7 & 121.9 & 1.6 & 0.08 & 0.02 & 195 & 1000 \\
\hline 5.2.1.1.8 & 62.4 & 2.5 & 0.1 & 0.02 & 156 & 1250 \\
\hline 1.1.1.1.7 & 97.5 & 1.6 & 0.08 & 0.02 & 156 & 1000 \\
\hline
\end{tabular}


Table 6. Hardness results and parameter settings for the blocks from Build \#17-16. Four replicate blocks for each of the nine settings are denoted by 1 to 4 after the block ID number.

\begin{tabular}{|c|c|c|c|c|c|c|c|c|}
\hline $\begin{array}{l}\text { BLOCK } \\
\text { ID }\end{array}$ & $\begin{array}{c}\text { HATCH } \\
\text { DISTANCE } \\
(\mathrm{mm})\end{array}$ & $\begin{array}{c}\text { LAYER } \\
\text { THICKNESS } \\
(\mathrm{mm})\end{array}$ & $\begin{array}{l}\text { LASER } \\
\text { POWER } \\
\text { (W) }\end{array}$ & $\begin{array}{l}\text { SCAN } \\
\text { SPEED } \\
(\mathrm{mm} / \mathrm{s})\end{array}$ & $\begin{array}{c}\text { VOLUME } \\
\text { RATE } \\
\left(\mathrm{mm}^{3} / \mathrm{s}\right)\end{array}$ & $\begin{array}{l}\text { ENERGY } \\
\text { DENSITY } \\
\left(\mathrm{J} / \mathrm{mm}^{3}\right)\end{array}$ & $\begin{array}{l}\text { HRC AVG } \\
\text { (STD DEV) }\end{array}$ & $\begin{array}{l}\text { HRC AVG } \\
\text { (STD DEV) }\end{array}$ \\
\hline 2.1.1.1.6-1 & 0.08 & 0.02 & 156 & 800 & 1.3 & 121.9 & $33.2(0.4)$ & \\
\hline 2.1.1.1.6-2 & 0.08 & 0.02 & 156 & 800 & 1.3 & 121.9 & $33.0(0.3)$ & \\
\hline 2.1.1.1.6-3 & 0.08 & 0.02 & 156 & 800 & 1.3 & 121.9 & $33.2(0.4)$ & \\
\hline 2.1.1.1.6-4 & 0.08 & 0.02 & 156 & 800 & 1.3 & 121.9 & $32.5(0.3)$ & \\
\hline $\begin{array}{c}\text { 2.1.1.1.6- } \\
\text { GRAND } \\
\text { AVG }\end{array}$ & & & & & & & & $\begin{array}{l}33.0 \\
(0.5)\end{array}$ \\
\hline 1.1.1.1.7-1 & 0.08 & 0.02 & 156 & 1000 & 1.6 & 97.5 & $32.5(0.4)$ & \\
\hline $1.1 .1 .1 .7-2$ & 0.08 & 0.02 & 156 & 1000 & 1.6 & 97.5 & $32.5(0.3)$ & \\
\hline $1.1 .1 .1 .7-3$ & 0.08 & 0.02 & 156 & 1000 & 1.6 & 97.5 & $32.4(0.4)$ & \\
\hline 1.1.1.1.7-4 & 0.08 & 0.02 & 156 & 1000 & 1.6 & 97.5 & $32.9(0.4)$ & \\
\hline $\begin{array}{c}\text { 1.1.1.1.7- } \\
\text { GRAND } \\
\text { AVG }\end{array}$ & & & & & & & & $\begin{array}{l}32.6 \\
(0.4)\end{array}$ \\
\hline 3.1.1.2.6-1 & 0.08 & 0.02 & 195 & 800 & 1.3 & 152.3 & $33.2(0.4)$ & \\
\hline 3.1.1.2.6-2 & 0.08 & 0.02 & 195 & 800 & 1.3 & 152.3 & $33.0(0.4)$ & \\
\hline $3.1 .1 .2 .6-3$ & 0.08 & 0.02 & 195 & 800 & 1.3 & 152.3 & $33.0(0.5)$ & \\
\hline 3.1.1.2.6-4 & 0.08 & 0.02 & 195 & 800 & 1.3 & 152.3 & $33.2(0.5)$ & \\
\hline $\begin{array}{c}\text { 3.1.1.2.6- } \\
\text { GRAND } \\
\text { AVG }\end{array}$ & & & & & & & & $\begin{array}{l}33.1 \\
(0.4)\end{array}$ \\
\hline 2.1.1.2.7-1 & 0.08 & 0.02 & 195 & 1000 & 1.6 & 121.9 & $32.9(0.3)$ & \\
\hline 2.1.1.2.7-2 & 0.08 & 0.02 & 195 & 1000 & 1.6 & 121.9 & $32.3(0.5)$ & \\
\hline 2.1.1.2.7-3 & 0.08 & 0.02 & 195 & 1000 & 1.6 & 121.9 & $32.4(0.3)$ & \\
\hline 2.1.1.2.7-4 & 0.08 & 0.02 & 195 & 1000 & 1.6 & 121.9 & $32.4(0.4)$ & \\
\hline $\begin{array}{c}\text { 2.1.1.2.7- } \\
\text { GRAND } \\
\text { AVG }\end{array}$ & & & & & & & & $\begin{array}{l}32.5 \\
(0.4)\end{array}$ \\
\hline 1.2.1.1.6-1 & 0.1 & 0.02 & 156 & 800 & 1.6 & 97.5 & $32.4(0.3)$ & \\
\hline $1.2 .1 .1 .6-2$ & 0.1 & 0.02 & 156 & 800 & 1.6 & 97.5 & $32.8(0.5)$ & \\
\hline $1.2 .1 .1 .6-3$ & 0.1 & 0.02 & 156 & 800 & 1.6 & 97.5 & $32.7(0.4)$ & \\
\hline $1.2 .1 .1 .6-4$ & 0.1 & 0.02 & 156 & 800 & 1.6 & 97.5 & $32.3(0.4)$ & \\
\hline $\begin{array}{c}\text { 1.2.1.1.6- } \\
\text { GRAND } \\
\text { AVG }\end{array}$ & & & & & & & & $\begin{array}{l}32.5 \\
(0.4)\end{array}$ \\
\hline 4.2.1.1.7-1 & 0.1 & 0.02 & 156 & 1000 & 2.0 & 78.0 & $31.9(0.4)$ & \\
\hline 4.2.1.1.7-2 & 0.1 & 0.02 & 156 & 1000 & 2.0 & 78.0 & $32.4(0.4)$ & \\
\hline $4 \cdot 2 \cdot 1 \cdot 1.7-3$ & 0.1 & 0.02 & 156 & 1000 & 2.0 & 78.0 & $32.2(0.3)$ & \\
\hline 4.2.1.1.7-4 & 0.1 & 0.02 & 156 & 1000 & 2.0 & 78.0 & $32.0(0.4)$ & \\
\hline
\end{tabular}




\begin{tabular}{|c|c|c|c|c|c|c|c|c|}
\hline $\begin{array}{c}\text { 4.2.1.1.7- } \\
\text { GRAND } \\
\text { AVG }\end{array}$ & & & & & & & & $\begin{array}{l}32.1 \\
(0.4)\end{array}$ \\
\hline 2.2.1.2.6-1 & 0.1 & 0.02 & 195 & 800 & 1.6 & 121.9 & $32.8(0.4)$ & \\
\hline 2.2.1.2.6-2 & 0.1 & 0.02 & 195 & 800 & 1.6 & 121.9 & $33.0(0.2)$ & \\
\hline 2.2.1.2.6-3 & 0.1 & 0.02 & 195 & 800 & 1.6 & 121.9 & $33.2(0.3)$ & \\
\hline $2.2 .1 .2 .6-4$ & 0.1 & 0.02 & 195 & 800 & 1.6 & 121.9 & $32.7(0.3)$ & \\
\hline $\begin{array}{c}2.2 .1 .2 .6- \\
\text { GRAND } \\
\text { AVG }\end{array}$ & & & & & & & & $\begin{array}{l}32.9 \\
(0.4)\end{array}$ \\
\hline 1.2.1.2.7-1 & 0.1 & 0.02 & 195 & 1000 & 2.0 & 97.5 & $32.4(0.5)$ & \\
\hline $1.2 .1 .2 .7-2$ & 0.1 & 0.02 & 195 & 1000 & 2.0 & 97.5 & $32.3(0.4)$ & \\
\hline $1.2 \cdot 1 \cdot 2.7-3$ & 0.1 & 0.02 & 195 & 1000 & 2.0 & 97.5 & $32.6(0.3)$ & \\
\hline $1.2 .1 .2 .7-4$ & 0.1 & 0.02 & 195 & 1000 & 2.0 & 97.5 & $32.3(0.4)$ & \\
\hline $\begin{array}{c}\text { 1.2.1.2.7- } \\
\text { GRAND } \\
\text { AVG }\end{array}$ & & & & & & & & $\begin{array}{l}32.4 \\
(0.4)\end{array}$ \\
\hline 5.2.1.1.8-1 & 0.1 & 0.02 & 156 & 1250 & 2.5 & 62.4 & $31.0(0.3)$ & \\
\hline 5.2.1.1.8-2 & 0.1 & 0.02 & 156 & 1250 & 2.5 & 62.4 & $31.1(0.3)$ & \\
\hline $5.2 .1 .1 .8-3$ & 0.1 & 0.02 & 156 & 1250 & 2.5 & 62.4 & $31.4(0.5)$ & \\
\hline $5.2 .1 .1 .8-4$ & 0.1 & 0.02 & 156 & 1250 & 2.5 & 62.4 & $31.2(0.4)$ & \\
\hline $\begin{array}{c}5.2 .1 .1 .8- \\
\text { GRAND } \\
\text { AVG }\end{array}$ & & & & & & & & $\begin{array}{l}31.1 \\
(0.4)\end{array}$ \\
\hline
\end{tabular}

For statistical analysis of the measured hardness values as a function of processing parameters, the 36 blocks were considered as manufactured with different combinations of four variables: energy density (5), hatch distance (2), laser power (2), and scan speed (3). The numbers between parentheses indicate the number of different values of each variable that are represented in the data. The layer thickness was the same $(0.02 \mathrm{~mm})$ for all blocks, hence it was not included in the statistical analysis. Since these process parameters are related to each other by Equation (1), it is expected that the influence of them on the resulting material hardness will be convoluted. Therefore, the statistical analysis was conducted by isolating the effects of individual process parameters, recognizing the fact that the influences of other parameters are hidden in the individual results. Nevertheless, the strength of the influence of individual process parameters can be identified with this approach. 
The measured hardness values are summarized graphically as boxplots according to the value of the scan speed (Figure 7). Each notched box comprises the middlemost $50 \%$ of the values of HRC measured in blocks corresponding to a specified level of scan speed, between its top and bottom, which represent the 75 th and 25 th percentiles of the measured values of HRC for this level of scan speed. The thick, horizontal line across the middle of each box represents the median for each scan speed data set. The widths of the boxes are proportional to the square roots of the number of measured HRC values that they represent. The whiskers (vertical dashed lines) attached to the top and bottom of each box, extend to the observation farthest from the top and bottom but no farther than 1.5 times the inter-quartile range (which is the height of the box, the difference between the values of HRC corresponding to its top and bottom). Measured values that lie beyond the end of the whiskers are potential outliers and are represented by red circles. The notches represent approximate coverage intervals for the medians of the values represented by the boxplots. If the notches of two boxplots do not overlap, then this is strong evidence that the two medians differ [16].

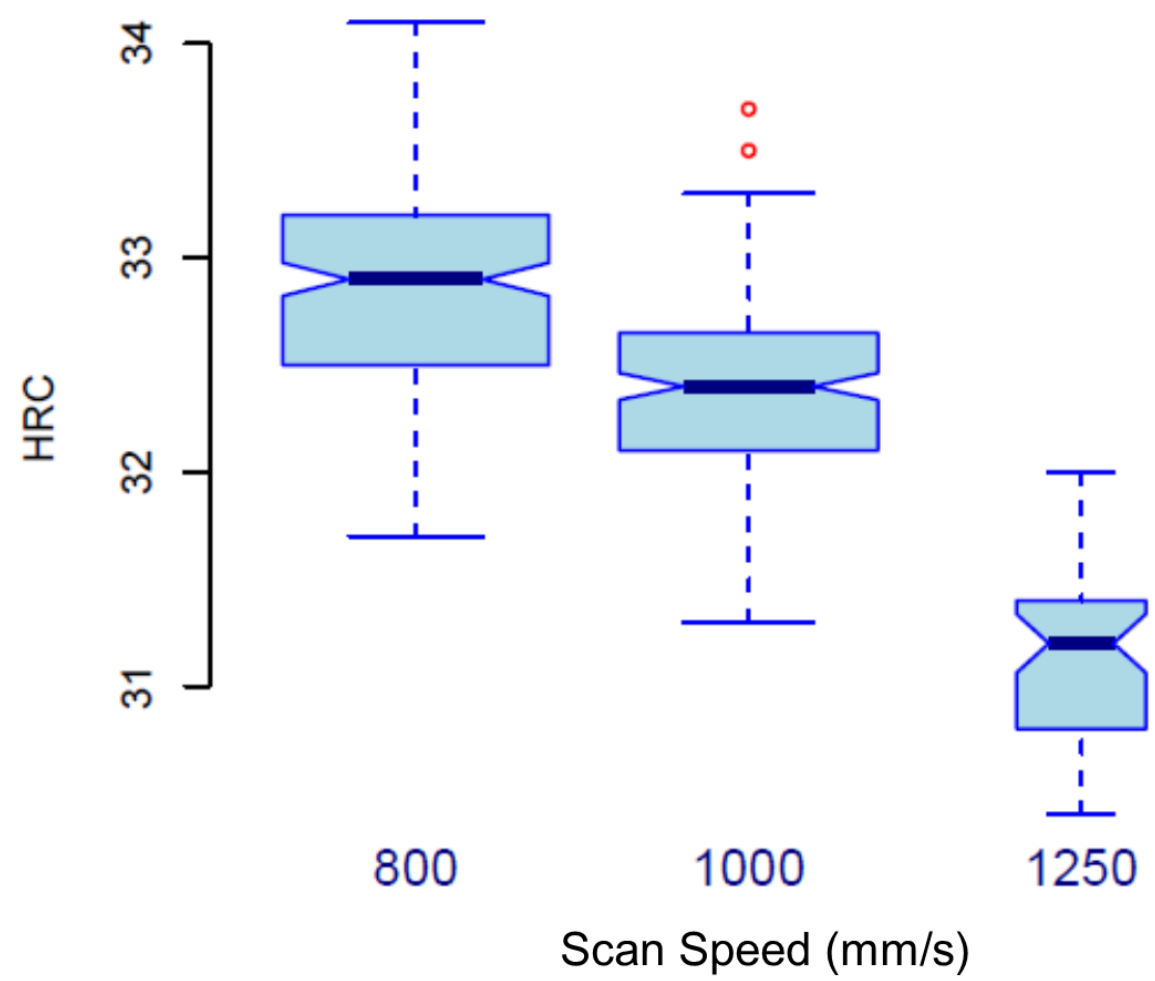

Figure 7. The relationship between the measured hardness and scan speed. 
This analysis demonstrates that hardness is inversely related to scan speed. The differences in hardness corresponding to different scan speeds are all statistically significant. A similar inverse relationship between scan speed and hardness was also found by Kempen et al. [1], Delgado et al. [5], and Song et al. [11] for several types of material on several AM systems. The lower hardness at the higher scan speed could be the result of insufficient melting of the powder (i.e., the laser travels too fast to thoroughly melt all powder particles). Unmelted or partially melted particles could then be trapped, forming pockets of gas, which would promote internal porosity and reduced hardness $[8,10]$.

The measured values of hardness are summarized graphically as boxplots according to the value of laser power (Figure 8). The laser power also has a statistically significant influence on hardness; the higher laser power tends to produce higher hardness. While the hardness increase is only slightly less than $0.5 \mathrm{HRC}$, as laser power is increased from $156 \mathrm{~W}$ to $195 \mathrm{~W}$, the difference is statistically significant. The lower hardness at lower levels of laser power can be attributed to the inability of the laser to sufficiently melt the powder at the different velocities. If the powder is not completely melted, internal porosity can occur leading to a less hard material. Previous research found that with increasing laser power, porosity decreased $[4,7,8,10]$, and with less porosity we expect an increase in hardness as we found in this study. O'Neill et al. concluded that higher energy density from higher laser power could vaporize the powder rather than melt it [12]. The gas pressure then propels the powder away from the melt pool resulting in porosity. 


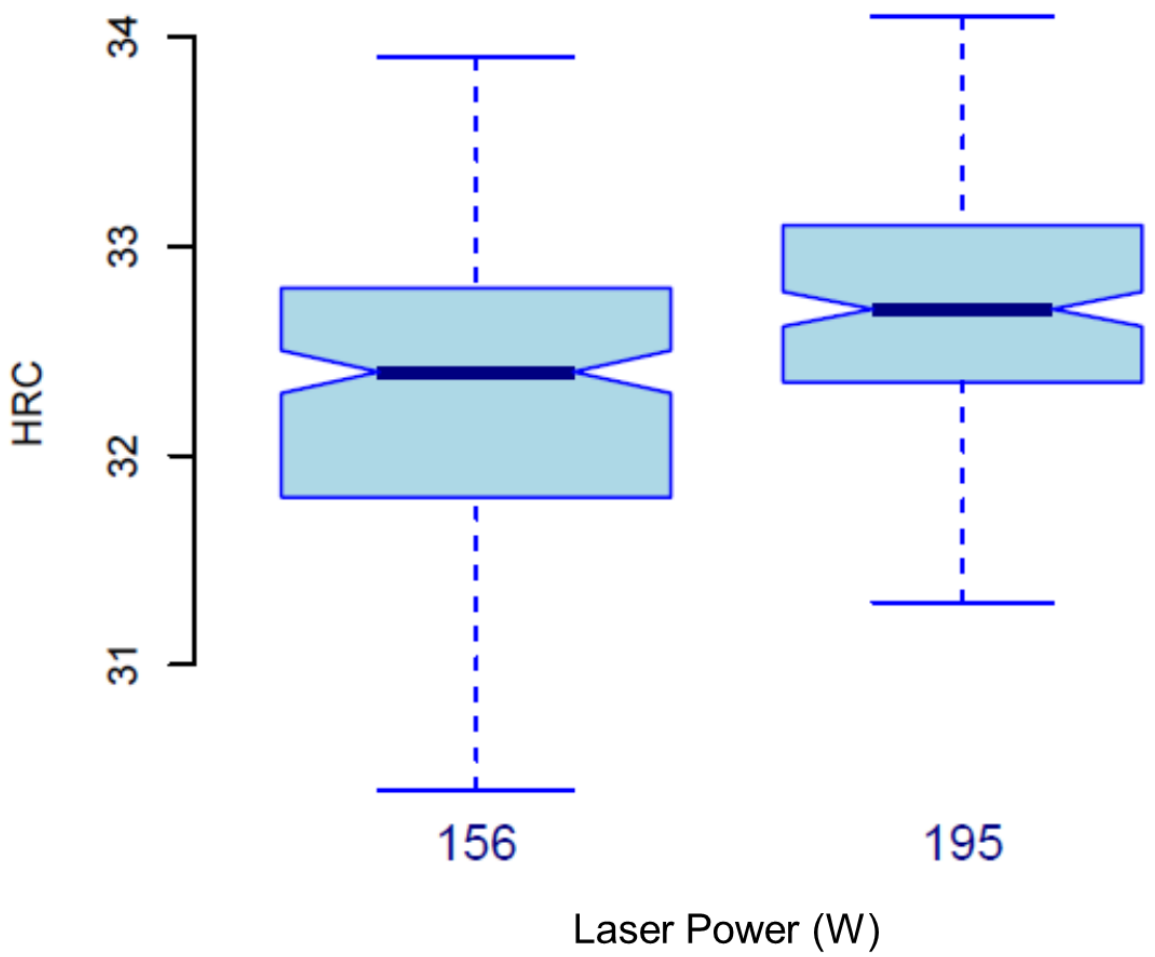

Figure 8 . The relationship between measured hardness and laser power.

The measured values of HRC are summarized graphically as boxplots according to the level of hatch distance (Figure 9). The hatch distance also has a statistically significant effect on hardness, with the narrower hatch distance tending to produce higher hardness than the wider hatch distance. The hardness decrease is less than $0.5 \mathrm{HRC}$, as the hatch distance changes from $0.08 \mathrm{~mm}$ to $0.1 \mathrm{~mm}$.

This relationship is expected based on previous research where an increase in hatch distance resulted in more porosity [8], and less density [2,6]. The more times the laser has a chance to melt a layer of powder as the laser overlaps the previous tracks, or re-melt a lower layer, it may result in a harder material. On the other hand, laser passes with a small hatch distance will add additional manufacturing time to make a part without yielding a much harder material. 


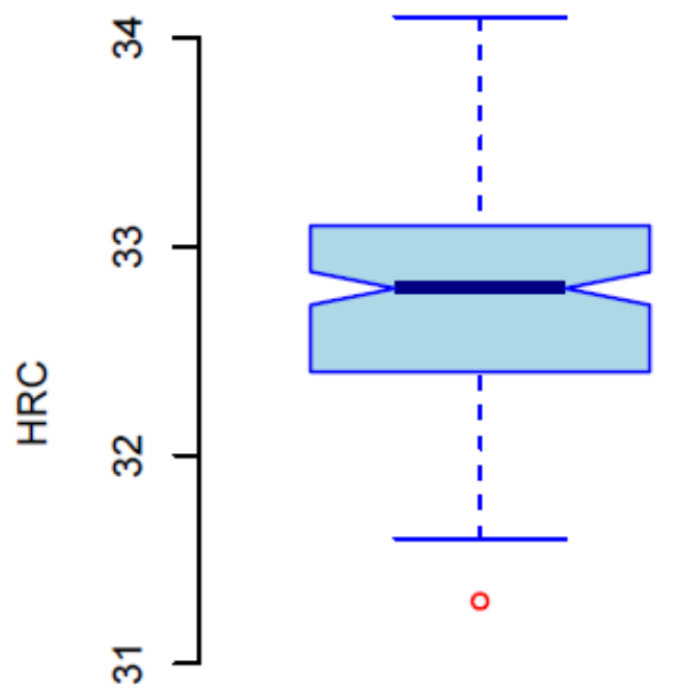

$0.08 \mathrm{~mm}$

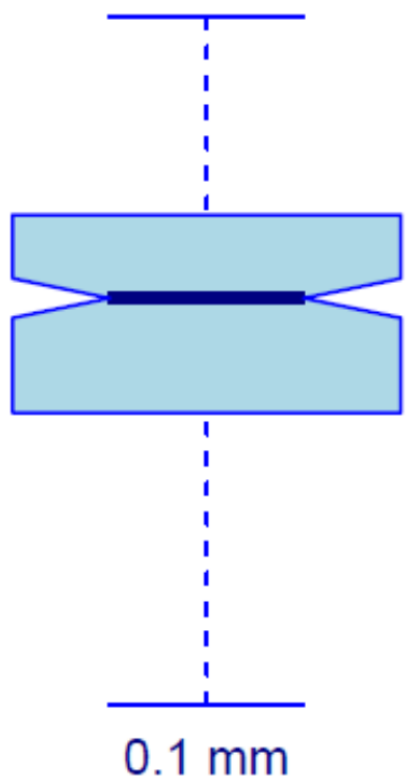

Hatch Distance

Figure 9. The relationship between the measured hardness and the hatch distance.

A plot of the values of HRC versus the corresponding values of energy density shows that the HRC increases non-linearly with increasing values of energy density (Figure 10). The red line represents a regression function of the form

$$
H=\alpha\left(1-\exp \left(-\beta E_{D}\right)\right)
$$

where $H$ is Rockwell $\mathrm{C}$ hardness, and $E_{D}$ is the energy density. The least-squares estimates of the parameters are $\hat{\alpha}=32.9 \mathrm{HRC}$ and $\hat{\beta}=0.0471 \mathrm{~mm}^{3} / \mathrm{J}$, with associated uncertainties $u(\hat{\alpha})=0.03 \mathrm{HRC}$ and $u(\hat{\beta})=0.0007 \mathrm{~mm}^{3} / \mathrm{J}$, and a correlation coefficient of -0.73 . The parameter $\alpha$ indicates the level of the plateau (value of HRC) towards which the curve is approaching. Since the regression curve is a model for the mean value of $\mathrm{HRC}$ at each value of energy density, the individual measured values are naturally scattered around this mean value. 


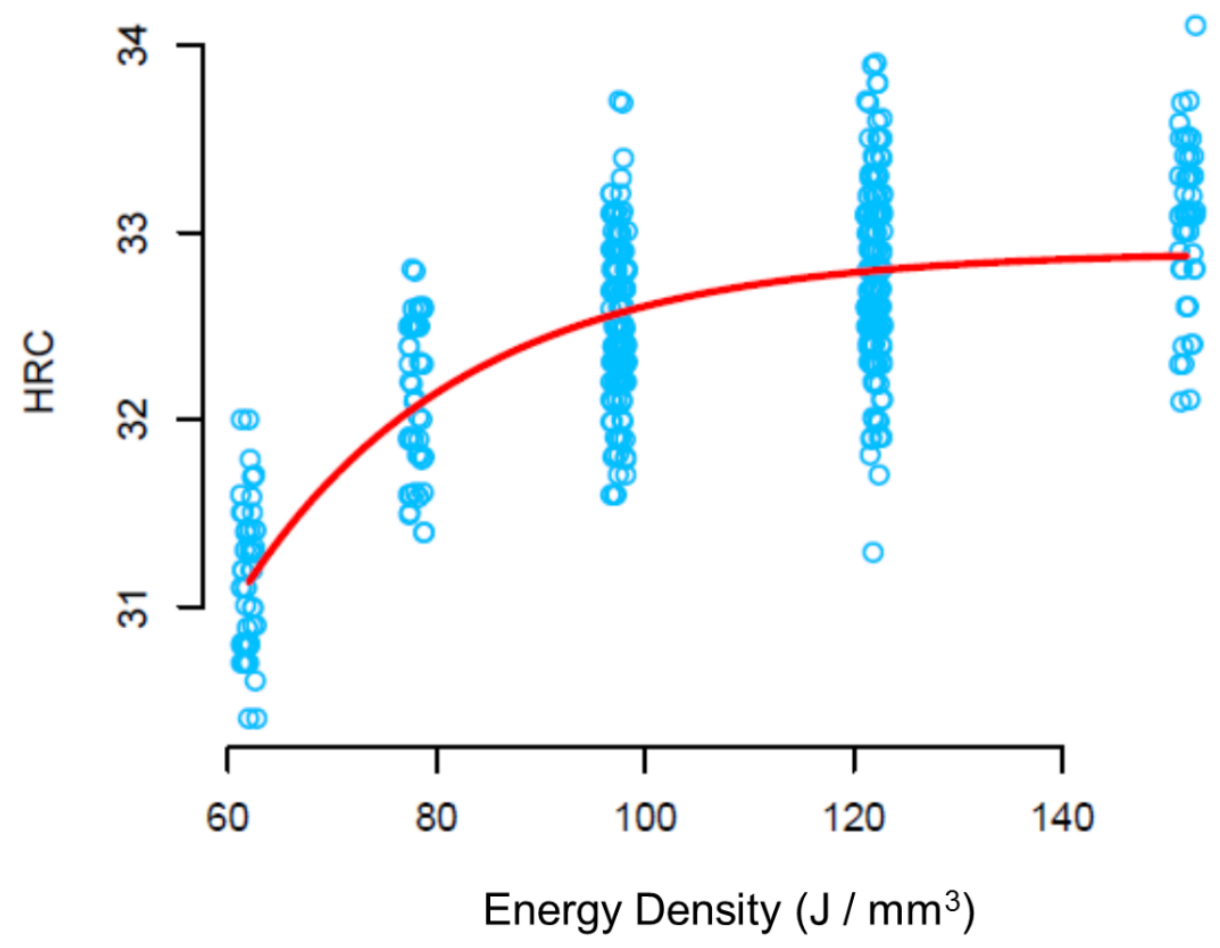

Figure 10. The relationship between the measured hardness and energy density.

The HRC increase is significant with increasing energy density, the rate of increase being largest for low values of energy density. Vandenbroucke and Kruth [6] found a similar relationship between energy density and both microindentation hardness and macroindentation hardness. The combination of settings that result in the calculated energy density appear to affect the hardness but only up to a point. For the range of settings in this experiment, it appears that the combination of settings results in a maximum hardness value of approximately $33 \mathrm{HRC}$. When the combination of settings results in an energy density less than $98 \mathrm{~J} / \mathrm{mm}^{3}$, the hardness of the material dramatically decreases.

Figure 11 compares energy density and hardness across the specific parameter settings. 


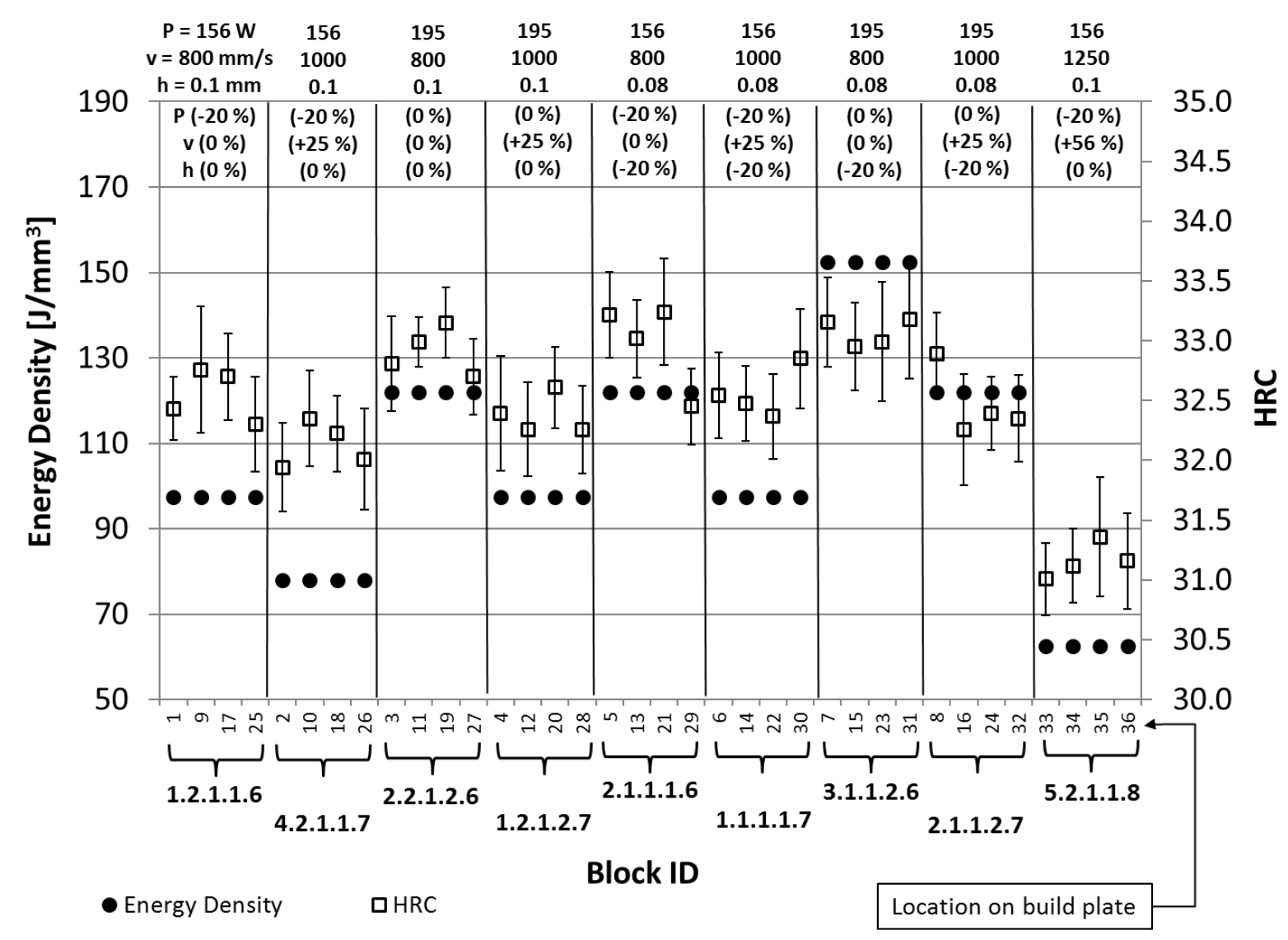

Figure 11. The relationship between energy density and hardness (HRC) for all blocks manufactured at the nine parameter settings. The values at the top of the figure are for laser power $(P)$, scan speed $(v)$, and hatch distance $(h)$ with a note about the setting as a percentage less (-) or greater $(+)$ than the recommended values used for block 2.2.1.2.6.

\subsection{Bulk Density}

After the hardness measurements were completed, seven blocks were chosen to determine the bulk density of the manufactured IN625 using helium gas pyncometry (Table 7). These seven blocks were chosen from Build \#2-16 and Build \#3-16 to represent the range of energy densities for Build \#17-16 (62.4 J/mm $\mathrm{mm}^{3}$ to $\left.152.3 \mathrm{~J} / \mathrm{mm}^{3}\right)$. Ten density measurements were made for each block to determine the average density and standard deviation. The machine vendor specified the predicted bulk density value of the manufactured IN625 material as $8.5 \mathrm{~g} / \mathrm{cm}^{3}$ using recommended machine settings. 
Table 7. Bulk density for the seven blocks measured using gas helium pyncometry. Block ID's with one asterisk (*) indicate a repeated measurement of the same block. Block ID's with two asterisks $(* *)$ indicate a second sample from the same block was used.

\begin{tabular}{|c|c|c|c|c|c|c|c|c|c|c|}
\hline \multirow{3}{*}{$\begin{array}{c}\begin{array}{c}\text { BLOCK } \\
\text { ID }\end{array} \\
2.2 .1 .2 .6\end{array}$} & \multicolumn{2}{|c|}{$\begin{array}{c}\text { BULK DENSITY } \\
\left(\mathrm{g} / \mathrm{cm}^{3}\right)\end{array}$} & \multicolumn{2}{|c|}{ HRC } & \multirow{3}{*}{$\begin{array}{c}\begin{array}{c}\text { ENERGY } \\
\text { DENSITY } \\
\left(\mathrm{J} / \mathrm{mm}^{3}\right)\end{array} \\
121.9\end{array}$} & \multirow{3}{*}{$\begin{array}{c}\begin{array}{c}\text { VOL } \\
\text { RATE } \\
\left(\mathrm{mm}^{3} / \mathrm{s}\right)\end{array} \\
1.6\end{array}$} & \multirow{3}{*}{$\begin{array}{c}\begin{array}{c}\text { HATCH } \\
\text { DIST } \\
(\mathrm{mm})\end{array} \\
0.1\end{array}$} & \multirow{3}{*}{$\begin{array}{c}\begin{array}{c}\text { LAYER } \\
\text { THICK } \\
(\mathrm{mm})\end{array} \\
0.02 \\
\end{array}$} & \multirow{3}{*}{$\begin{array}{c}\text { LASER } \\
\text { POWER } \\
\text { (W) } \\
195\end{array}$} & \multirow{3}{*}{$\begin{array}{c}\begin{array}{c}\text { SCAN } \\
\text { SPEED } \\
(\mathrm{mm} / \mathrm{s})\end{array} \\
800\end{array}$} \\
\hline & \multicolumn{2}{|c|}{ AVG STD } & \multicolumn{2}{|c|}{ AVG STD } & & & & & & \\
\hline & 8.5099 & 0.0041 & 36.4 & 0.1 & & & & & & \\
\hline 2.2.1.2.6* & 8.4986 & 0.0023 & 36.4 & 0.1 & 121.9 & 1.6 & 0.1 & 0.02 & 195 & 800 \\
\hline 1.2.1.2.7 & 8.5164 & 0.0046 & 35.1 & 0.3 & 97.5 & 2.0 & 0.1 & 0.02 & 195 & 1000 \\
\hline 1.1.1.1.7 & 8.5423 & 0.0105 & 35.9 & 0.3 & 97.5 & 1.6 & 0.08 & 0.02 & 156 & 1000 \\
\hline 1.1.1.1.7** & 8.5290 & 0.0103 & 35.9 & 0.3 & 97.5 & 1.6 & 0.08 & 0.02 & 156 & 1000 \\
\hline 1.1.1.1.7* & 8.5245 & 0.0064 & 35.9 & 0.3 & 97.5 & 1.6 & 0.08 & 0.02 & 156 & 1000 \\
\hline 3.1.1.2.6 & 8.5075 & 0.0047 & 36.2 & 0.2 & 152.3 & 1.3 & 0.08 & 0.02 & 195 & 800 \\
\hline 5.2.1.1.8 & 8.4606 & 0.0052 & 33.8 & 0.2 & 62.4 & 2.5 & 0.1 & 0.02 & 156 & 1250 \\
\hline $5.2 .1 .1 .8^{* *}$ & 8.4570 & 0.0052 & 33.8 & 0.2 & 62.4 & 2.5 & 0.1 & 0.02 & 156 & 1250 \\
\hline 4.2.1.1.7 & 8.5032 & 0.0047 & 34.8 & 0.3 & 78.0 & 2.0 & 0.1 & 0.02 & 156 & 1000 \\
\hline $4.2 .1 .1 .7^{* *}$ & 8.4978 & 0.0067 & 34.8 & 0.3 & 78.0 & 2.0 & 0.1 & 0.02 & 156 & 1000 \\
\hline 1.2.1.1.6 & 8.5110 & 0.0046 & 35.8 & 0.4 & 97.5 & 1.6 & 0.1 & 0.02 & 156 & 800 \\
\hline
\end{tabular}

Figure 12 shows the average bulk density and hardness measurements for the blocks over the range of energy densities. The measured bulk density compares well to the predicted value by the powder supplier of $8.5 \mathrm{~g} / \mathrm{cm}^{3}$ for energy densities of $78 \mathrm{~J} / \mathrm{mm}^{3}$ and above.

Similar to what was observed with the measured HRC data, the average bulk density also increased non-linearly with increasing values of energy density. The rate of increase was the largest for low values of energy density, eventually plateauing as the energy density reached the highest values for this study. Increasing bulk density with increasing energy density was also shown by Gu et al. [10], Simchi et al. [17], and Vandenbroucke and Kruth [6] using other metal powders and AM processes. Liu et al. [9] and Kempen et al. [1] also found that decreasing scan speed, which causes an increase in energy density, resulted in a corresponding increase in density. 


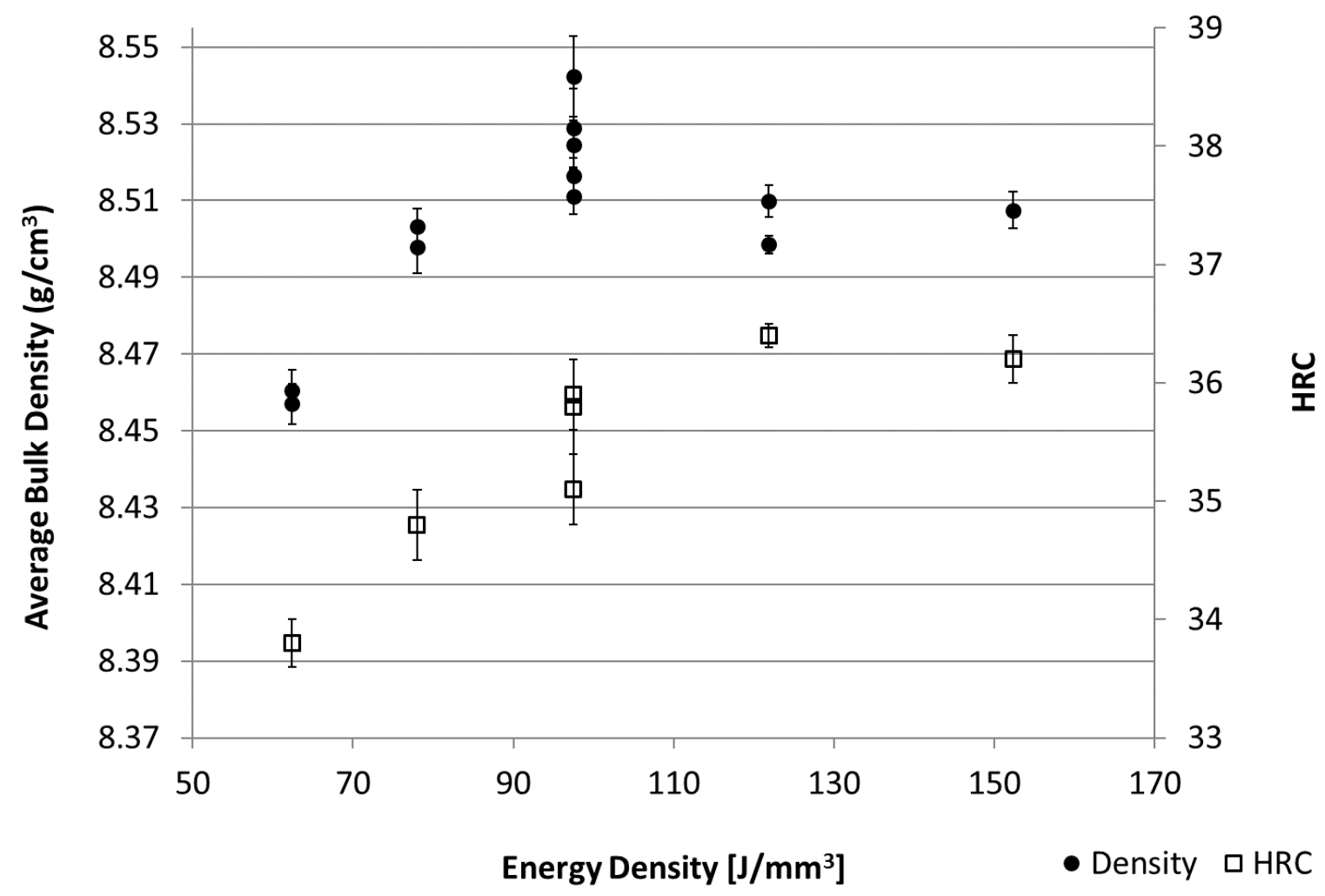

Figure 12. Average bulk density and HRC compared to energy density for measurements taken from the seven blocks.

\section{Conclusions}

The goal of this study was to investigate the relationship between mechanical and material properties (including density) of manufactured IN625 using a laser powder bed fusion process and three process parameters: laser power, hatch distance, and scan speed. For the $800 \mathrm{~mm} / \mathrm{s}$ to $1250 \mathrm{~mm} / \mathrm{s}$ laser scan speed range used in this study, the scan speed was shown to have a statistically significant influence on hardness. That is the hardness decreased significantly with increasing scan speed. Increasing the laser power from $156 \mathrm{~W}$ to $195 \mathrm{~W}$ was also shown to have a statistically significant effect on hardness. The higher laser power tended to produce higher hardness in a test block than lower laser power. The hatch distance was also shown to have a statistically significant effect on hardness, where the narrower 
hatch distance tended to produce higher hardness in a test block than the wider hatch distance. As the hatch distance increased from $0.08 \mathrm{~mm}$ to $0.1 \mathrm{~mm}$, the hardness decreased.

The HRC increases significantly, but non-linearly, with increasing energy density. The rate of this increase is largest for low values of energy density, and it eventually levels out as the energy density reaches its highest values represented in this experiment of 33 HRC.

The average bulk density also increases non-linearly with increasing values of energy density similar to measured HRC values. The bulk density rate of increase is the largest for low values of energy density, eventually leveling out as energy density reaches its peak value at or above $8.5 \mathrm{~g} / \mathrm{cm}^{3}$.

The results of this study provide guidance for choosing the range of parameter settings for future AM round robin studies coordinated by NIST. 


\section{References}

[1] Kempen K, Yasa E, Thijs L, Kruth JP, Humbeeck JV (2011) Microstructure and mechanical properties of selective laser melted 18Ni-300 steel. Physics Procedia, 12:255263. doi:10.1016/j.phpro.2011.03.033.

[2] Sun J, Yang Y, and Wang D (2013) Parametric optimization of selective laser melting for forming Ti6Al4V samples by Taguchi method. Optics \& Laser Technology 49:118-124. doi:10.1016/j.optlastec.2012.12.002.

[3] Deffley RJ (2012) Development of Processing Strategies for the Additive Layer Manufacture of Aerospace Components in Inconel 718. PhD, University of Sheffield. http://ethos.bl.uk/OrderDetails.do?uin=uk.bl.ethos.574588

[4] Dingal S, Pradhan TR, Sarin Sundar JK, Choudhury AR, Roy SK (2008) The application of Taguchi's method in the experimental investigation of the laser sintering process. International Journal of Advanced Manufacturing Technology 38:904-914. Doi:10.1007/s00170-007-1154-1.

[5] Delgado J, Ciurana J, and Rodríguez CA (2012) Influence of process parameters on part quality and mechanical properties for DMLS and SLM with iron-based materials. The International Journal of Advanced Manufacturing Technology 60:601-610. doi:10.1007/s00170-011-3643-5.

[6] Vandenbroucke B, Kruth JP (2007) Selective laser melting of biocompatible metals for rapid manufacturing of medical parts. Rapid Prototyping Journal 13:196-203. doi:10.1108/13552540710776142.

[7] Qiu C, Adkins NJE, Attallah MM (2013) Microstructure and tensile properties of selectively laser-melted and of HIPed laser-melted Ti-6Al-4V. Materials Science and Engineering A578:230-239. doi:10.1016/j.msea.2013.04.099.

[8] Abele E, Stoffregen HA, Kniepkamp M, Lang S, and Hampe M (2015) Selective laser melting for manufacturing of thin-walled porous elements. Journal of Materials Processing Technology 215:114-22. doi:10.1016/j.jmatprotec.2014.07.017.

[9] Liu B, Wildman R, Tuck C, Ashcroft I, Hague R, (2011) Investigation the effect of particle size distribution on processing parameters optimisation in selective laser melting process. Proceedings of Solid Freeform Fabrication Symposium, 227-238.

[10] Gu H, Gong H, Pal D, Rafi K, Starr T, and Stucker B (2013) Influences of energy density on porosity and microstructure of selective laser melted 17-4PH stainless steel. Proceedings of Solid Freeform Fabrication Symposium, 474-489. 
[11] Song B, Dong S, Coddet P, Liao H, Coddet C (2014) Fabrication of NiCr alloy parts by selective laser melting: columnar microstructure and anisotropic mechanical behavior. Materials \& Design 53:1-7. doi:10.1016/j.matdes.2013.07.010.

[12] O'Neill W, Sutcliffe CJ, Morgan R, Landsborough A, Hon KKB, (1999) Investigation on multi layer direct metal laser sintering of $316 \mathrm{~L}$ stainless steel powder beds. Annals of the CIRP, 48(1): 151-154.

[13] Yadroitsev I, Yadroitsava I, Bertrand P, Smurov I (2012) Factor analysis of selective laser melting process parameters and geometrical characteristics of synthesized single tracks. Rapid Prototyping Journal 18:201-208. doi:10.1108/13552541211218117.

[14] R Core Team. R: A Language and Environment for Statistical Computing. R Foundation for Statistical Computing, Vienna, Austria, 2016. URL www.R-project.org/.

[15] Venables WN, Ripley BD (2002) Modern Applied Statistics, S. Springer, New York, Fourth edition. URL www.stats.ox.ac.uk/pub/MASS4. ISBN 0-387-95457-0.

[16] Chambers J, Cleveland W, Kleiner B, and Tukey P (1983) Graphical Methods for Data Analysis, Wadsworth, Belmont, CA.

[17] Simchi A, Petzoldt F, Pohl H (2003) On the development of direct metal laser sintering for rapid tooling. J of Materials Processing Technology 141:319-328.

[18] Vander Voort GF: Metallography Principles and Practice, ASM International, Materials Park, OH, 1999. 


\section{Appendix A: Build Drawing and Build Report for Build \#2-16}
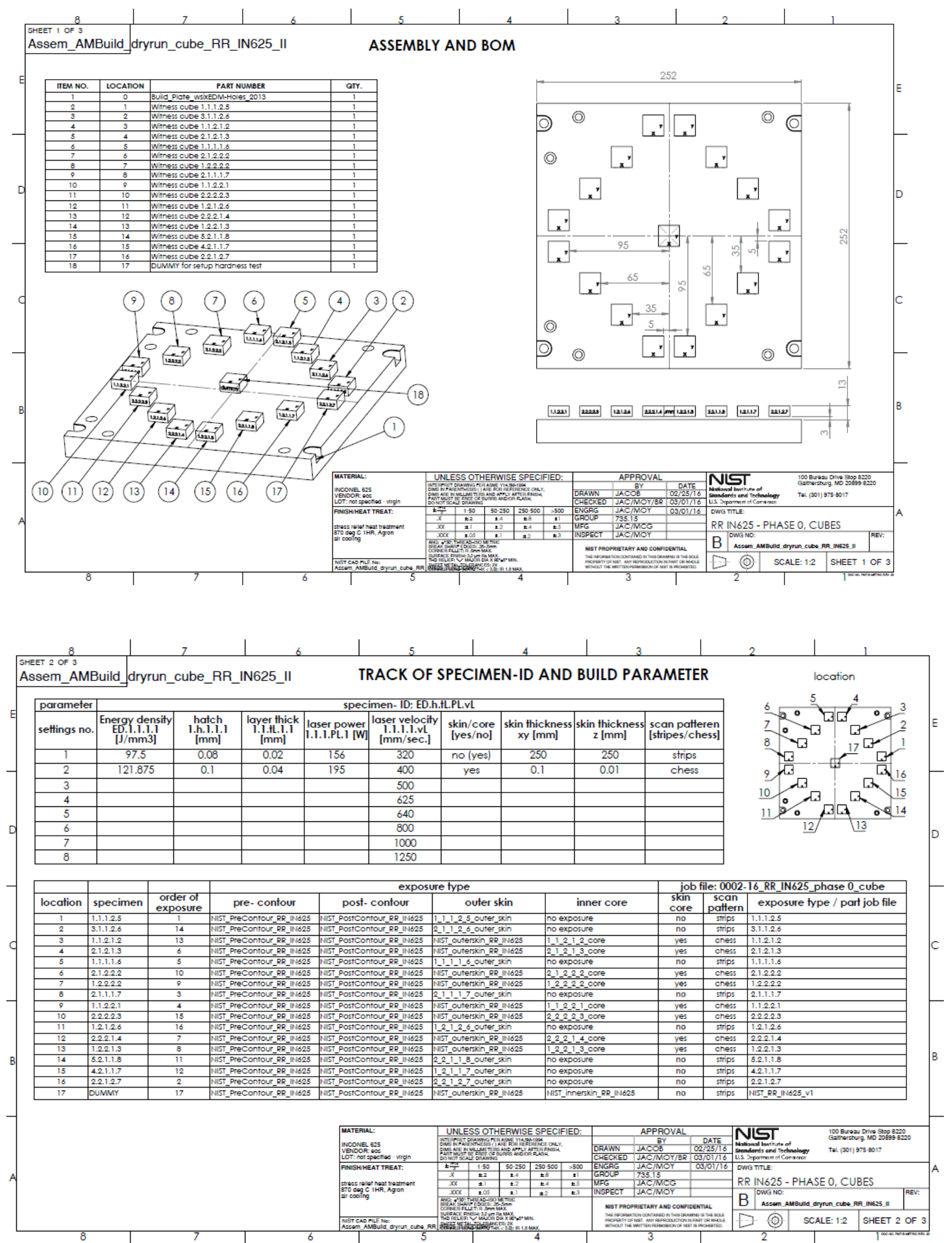


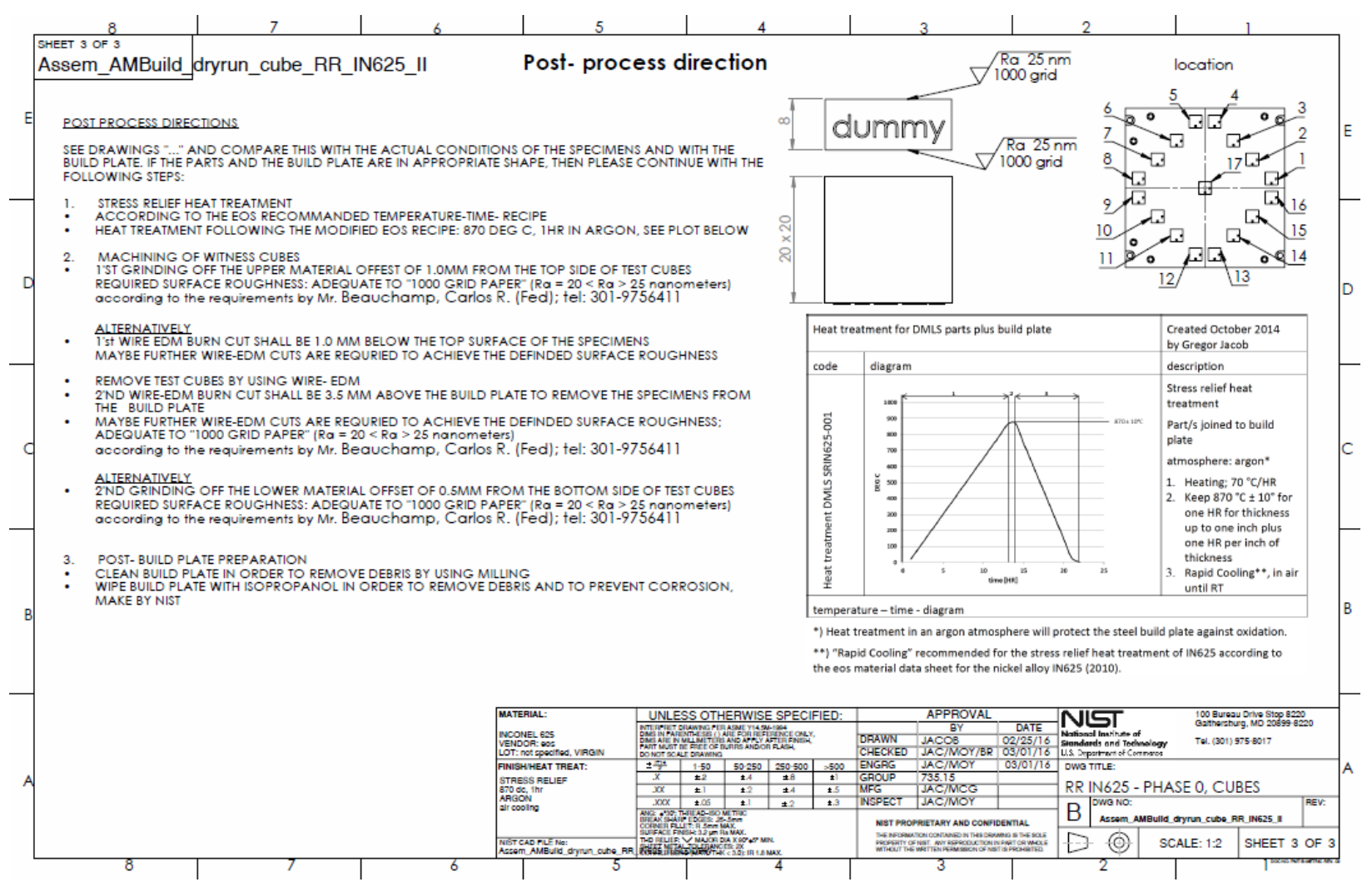




\begin{tabular}{|c|c|c|c|}
\hline $\begin{array}{l}\text { NGT } \\
\text { Nahional Instimum of } \\
\text { Standards and Technology } \\
\text { U.S. Departmert of Commerce }\end{array}$ & $\begin{array}{c}\text { build job - log } \\
\text { EOS - M270 } \\
\text { EOS LABORATORY }\end{array}$ & & $\begin{array}{c}2016 \\
03 \text { с } / 02\end{array}$ \\
\hline \multicolumn{4}{|l|}{ Build job end: } \\
\hline build successfully finished: & & \begin{tabular}{|l|l|}
$x$ & yes \\
\end{tabular} & no \\
\hline \multicolumn{4}{|l|}{ Project registration: } \\
\hline project name: & \multicolumn{2}{|l|}{ Round Robin IN625 FY16 } & $\begin{array}{c}\text { build- no.: } \\
0002-16\end{array}$ \\
\hline build file name: & \multicolumn{3}{|l|}{ 0002-16_RR_IN625_Phase0_cube } \\
\hline \multicolumn{4}{|l|}{ customer / partner: } \\
\hline \multicolumn{4}{|l|}{ customer's name of project: } \\
\hline description (short): & \multicolumn{3}{|l|}{ Cube with two different Energy density } \\
\hline \multicolumn{4}{|l|}{ Operator registration: } \\
\hline name: & Mike / Gregor & extension: & $\mathrm{X} 8017$ \\
\hline \multicolumn{4}{|l|}{ Description of part/s to build: } \\
\hline $\begin{array}{l}\text { name build element/s: } \\
\text { (sketch) }\end{array}$ & Test cubes & quantity: & \begin{tabular}{|l|}
$17 \mathrm{x}$ \\
$\ldots$ \\
$\ldots$ \\
$\ldots$ \\
$\ldots$ \\
$\ldots$ \\
\end{tabular} \\
\hline $\begin{array}{l}\text { dimension of element/s } \\
\mathrm{h} / \mathrm{w} / \mathrm{d}[\mathrm{mm}]:\end{array}$ & \multicolumn{3}{|l|}{$\begin{array}{l}20 \times 20 \times 10+3 \text { support } \\
\ldots\end{array}$} \\
\hline
\end{tabular}

\section{Build plate:}

\begin{tabular}{|l|l|l|l|l|l|l|}
\hline build plate no: & $\ldots$ & $\times$ & EOS; $250 \times 250 \mathrm{~mm}$ & \multicolumn{3}{l|}{ regular plate } \\
\hline thickness [mm] & $\ldots$ & & NIST; $4 \times: 100 \times 100 \mathrm{~mm}$ & \multicolumn{3}{l|}{ experimental plate } \\
\hline EDM holes & & no & x & yes \\
\hline temperature [celcius] & pre-heat: 80 & build: & 80 \\
\hline
\end{tabular}

\section{Material:}

\begin{tabular}{|c|c|c|c|c|c|}
\hline material : & \multicolumn{3}{|l|}{ Inconel 625} & material- ID: & \\
\hline powder producer / supplier: & \multicolumn{3}{|l|}{ EOS } & LOT-no.: & M111201-2 \\
\hline powder condition: & \begin{tabular}{l|l}
$\mathrm{x}$ & virgin \\
\end{tabular} & used & others: & & \\
\hline \multicolumn{6}{|l|}{ size fraction $[\mu \mathrm{m}]$ : } \\
\hline name material setup M270: & \multicolumn{5}{|c|}{ MP1_20_100_IN625_040_NIST_v1 } \\
\hline layer thickness $[\mu \mathrm{m}]$ : & \multicolumn{5}{|c|}{20 and 40 depends on part setting } \\
\hline
\end{tabular}

\section{Atmosphere:}

\begin{tabular}{|l|l|l|l|l|}
\hline build gas atmosphere: & $\mathrm{x}$ & nitrogen / generator & argon 4.6 / 5.0 \\
\hline
\end{tabular}

\begin{tabular}{|c|c|c|c|c|}
\hline \multirow{3}{*}{$\begin{array}{l}\text { name exposure parameter: } \\
\text { strategy: } \\
\text { skin thickness: }\end{array}$} & \multicolumn{4}{|c|}{ Depends on cube } \\
\hline & \multicolumn{2}{|c|}{\begin{tabular}{l|l}
$x$ & skin
\end{tabular}} & \multicolumn{2}{|c|}{\begin{tabular}{l|l}
$\mathbf{x}$ & skin / core
\end{tabular}} \\
\hline & $x y(m m)$ & 0.1 and 250 & $z(\mathrm{~mm})$ & 0.01 and 250 \\
\hline \multicolumn{5}{|c|}{ Recoater setup: } \\
\hline kind of recoater blade: & \multicolumn{2}{|c|}{ ceramic } & \multicolumn{2}{|c|}{ HSS } \\
\hline recoater charge factor [\%]: & MIN: & 100 & MAX: & 100 \\
\hline
\end{tabular}


Further Settings (optional):

Strategy / order of part exposure:

\begin{tabular}{|l|l|l|l|l|l|l|}
\hline \multicolumn{1}{|l|}{ part size } & & left to right & $\mathrm{x}$ & front to back & & others \\
\hline $\begin{array}{l}\text { description: } \\
\text { counter clockwise between front and back }\end{array}$ & \\
\hline
\end{tabular}

Setting of exposure parameters:

\begin{tabular}{|l|l|l|l|l|l|}
\hline actual parameter & E.1.1.1.1 & $1 . h .1 .1 .1$ & $1.1 . t .1 .1$ & $1.1 .1 . p l .1$ & $1.1 .1 .1 . v l$ \\
\hline Name & energy & $\mathrm{h}$ & $\mathrm{t}$ & $\mathrm{pl}$ & $\mathrm{vl}$ \\
\hline 1.1 .1 .2 .5 & 190.4 & 0.08 & 0.02 & 195 & 640 \\
\hline 2.2 .1 .2 .7 & 121.9 & 0.1 & 0.02 & 195 & 800 \\
\hline 2.1 .1 .1 .7 & 97.5 & 0.08 & 0.02 & 156 & 1000 \\
\hline 1.1 .2 .2 .1 & 190.4 & 0.08 & 0.04 & 195 & 320 \\
\hline 1.1 .1 .1 .6 & 121.9 & 0.08 & 0.02 & 156 & 800 \\
\hline 2.1 .2 .1 .3 & 97.5 & 0.08 & 0.04 & 156 & 500 \\
\hline 2.2 .2 .1 .4 & 62.4 & 0.1 & 0.04 & 156 & 625 \\
\hline 1.2 .2 .1 .3 & 78.0 & 0.1 & 0.04 & 156 & 500 \\
\hline 1.2 .2 .2 .2 & 121.9 & 0.1 & 0.04 & 195 & 400 \\
\hline 2.1 .2 .2 .2 & 152.3 & 0.08 & 0.04 & 195 & 400 \\
\hline 5.2 .1 .1 .8 & 62.4 & 0.1 & 0.02 & 156 & 1250 \\
\hline 4.2 .1 .1 .7 & 78.0 & 0.1 & 0.02 & 156 & 1000 \\
\hline 1.1 .2 .1 .2 & 121.9 & 0.08 & 0.04 & 156 & 400 \\
\hline 3.1 .1 .2 .6 & 152.3 & 0.08 & 0.02 & 195 & 800 \\
\hline 2.2 .2 .3 & 97.5 & 0.1 & 0.04 & 195 & 500 \\
\hline 1.2 .1 .2 .6 & 121.9 & 0.1 & 0.02 & 195 & 800 \\
\hline & & & & & \\
\hline
\end{tabular}

Time of build operations:

\begin{tabular}{|l|l|l|l|}
\hline start pre-flooding: AM/PM & \multicolumn{3}{|l|}{} \\
\hline start job: AM/PM & $\ldots$ & real build time [hh:mm]: & $\sim 17$ hrs \\
\hline estimated build time [hh:mm] & $\ldots$ & \\
\hline
\end{tabular}

Notes / observation during the build:

observation:

build time / layer / height:

\section{Observation on part/s:}

observation:

layer / height

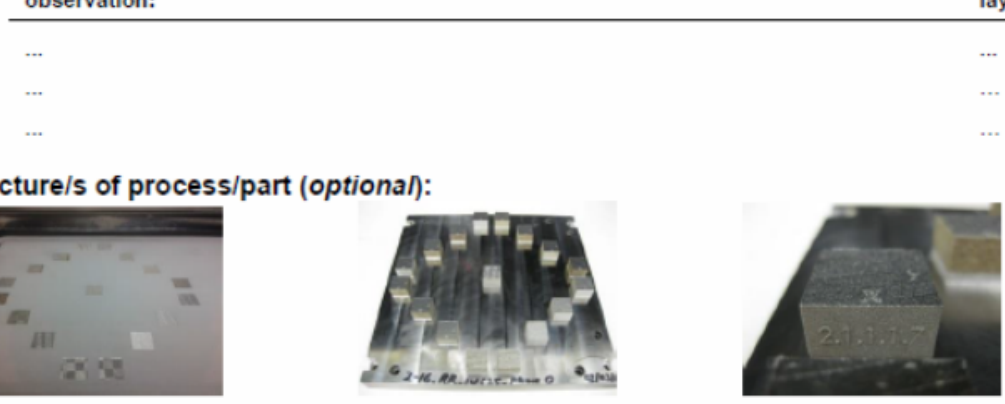




\section{Appendix B: Build Drawing and Build Report for Build \#3-16}
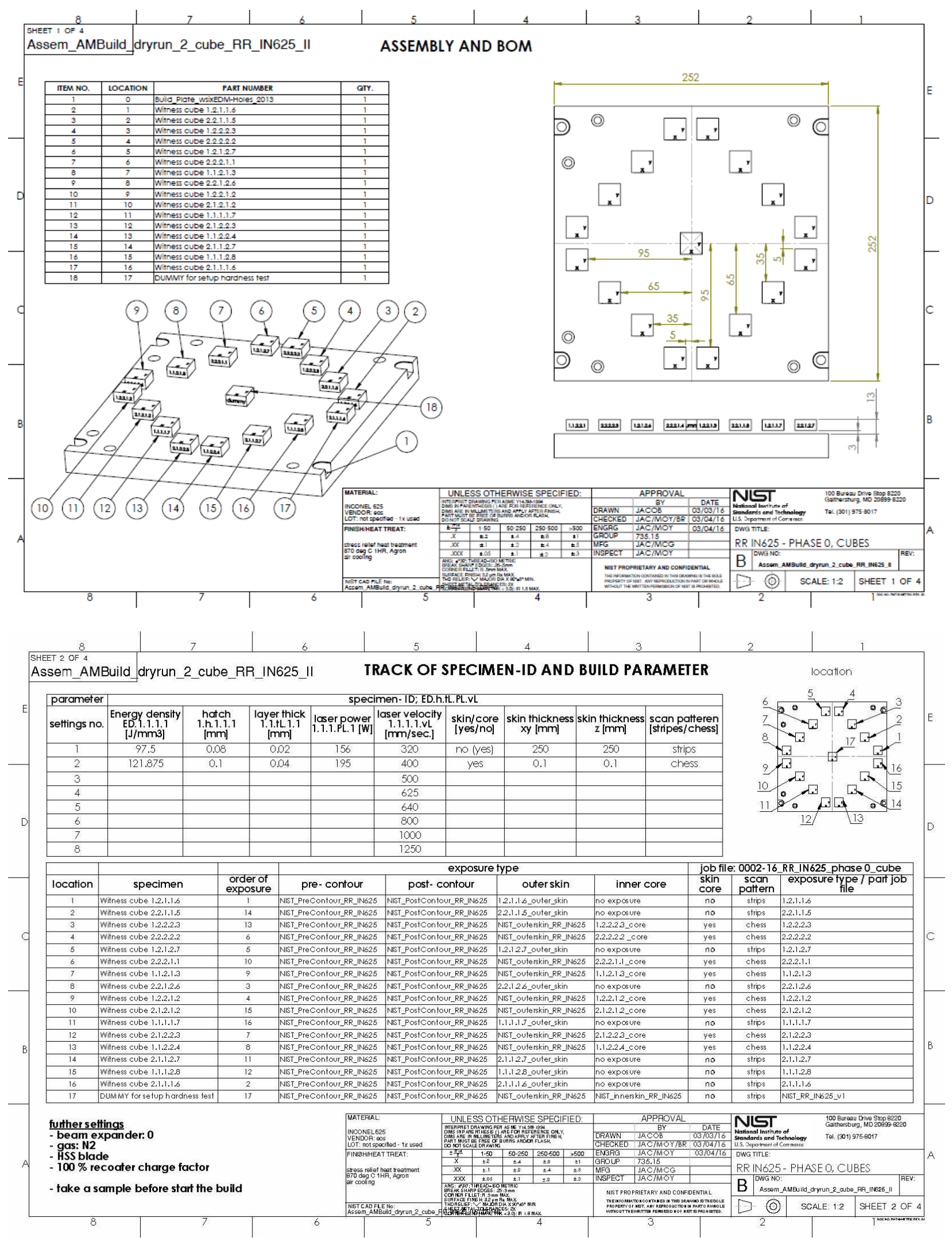

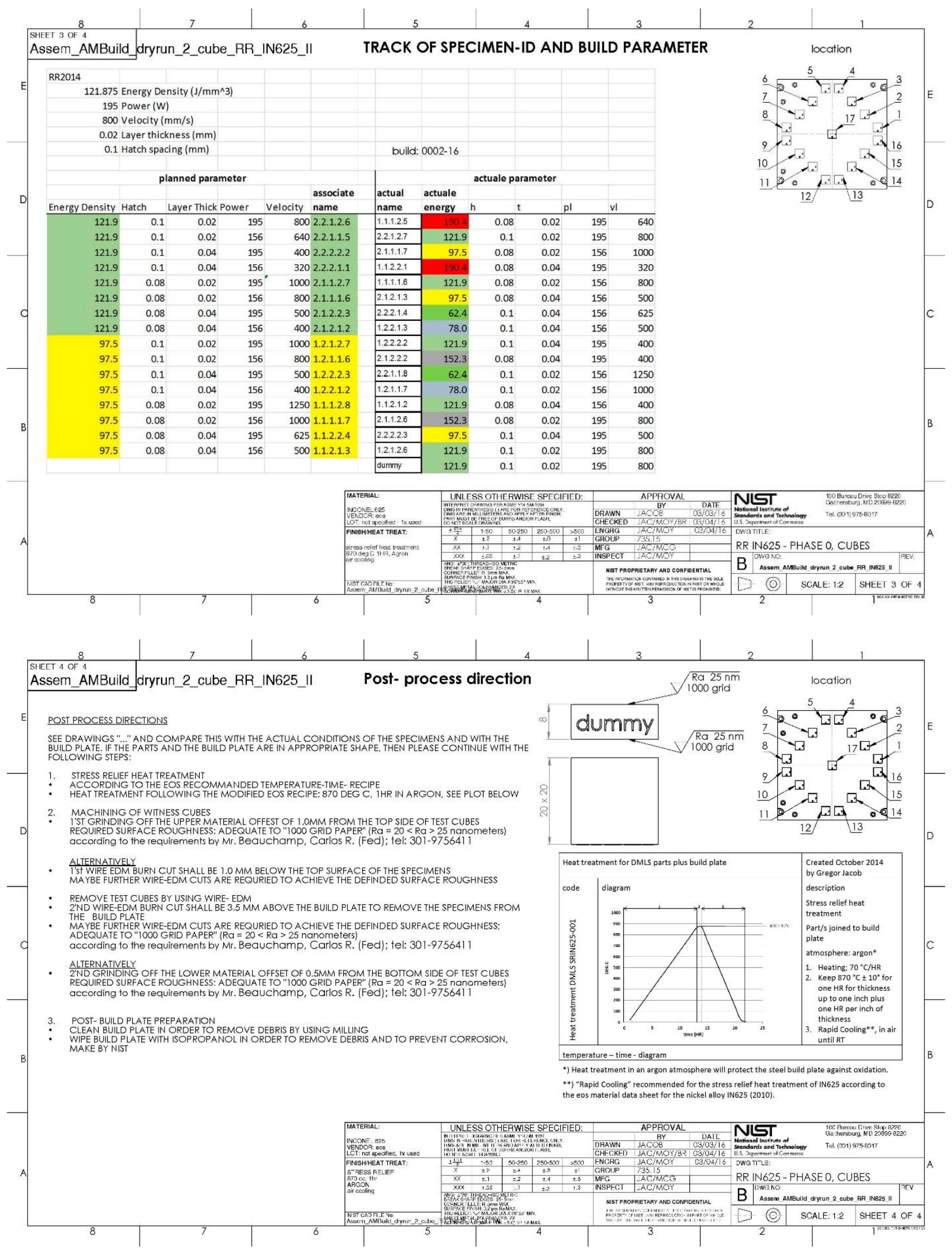


\begin{tabular}{|l|c|c|}
\hline NLST & build job - log & 2016 \\
$\substack{\text { National Institute of } \\
\text { Standards ond Technology } \\
\text { U.S. Deportment of Commerce }}$ & EOS - M270 & 2016 \\
EOS LABORATORY & 03 & $03 / 08$ \\
\hline
\end{tabular}

Build job end:

\begin{tabular}{|l|l|l|l|}
\hline build successfully finished: & $\mathrm{x}$ & yes & no \\
\hline
\end{tabular}

Project registration:

\begin{tabular}{|l|l|c|}
\hline project name: & RR IN625 FY16 & $\begin{array}{c}\text { build-no.: } \\
\text { 0003-15 }\end{array}$ \\
\hline build file name: & 0003-16_IN625_Phase0_cube.eosjob & \\
\hline
\end{tabular}

\begin{tabular}{|l|l|}
\hline customer / partner: & $\ldots$ \\
\hline customer's name of project: & $\ldots$ \\
\hline description (short): & Two energy density with different settings of $\mathrm{Pl}, \mathrm{vl}, \mathrm{h}, \mathrm{tl}$ \\
\hline
\end{tabular}

Operator registration:

\begin{tabular}{|l|l|l|l|}
\hline name: & Jacob, Mc Glauflin & extension: & X8017 \\
\hline
\end{tabular}

Description of part/s to build:

\begin{tabular}{|l|l|l|l|}
\hline $\begin{array}{l}\text { name build element/s: } \\
\text { (sketch) }\end{array}$ & cubes & quantity: & $17 x$ \\
& $\ldots$ & & $\ldots$ \\
& $\ldots$ & & $\ldots$ \\
& $\ldots$ & $\ldots$ \\
\hline $\begin{array}{l}\text { dimension of element/s } \\
\text { h/w/d [mm]: }\end{array}$ & $\ldots$ & & $\ldots$ \\
\hline
\end{tabular}

Build plate:

\begin{tabular}{|l|l|l|l|l|l|}
\hline build plate no: & 02 & $\mathrm{x}$ & EOS; $250 \times 250 \mathrm{~mm}$ & \multicolumn{2}{l|}{ regular plate } \\
\hline thickness [mm] & $\ldots$ & NIST; $4 \times: 100 \times 100 \mathrm{~mm}$ & \multicolumn{2}{|l|}{ experimental plate } \\
\hline EDM holes & \multicolumn{1}{|l|}{ no } & x & yes \\
\hline temperature [celcius] & pre-heat: & 80 & build: & 80 \\
\hline
\end{tabular}

Material:

\begin{tabular}{|c|c|c|c|c|c|c|}
\hline material: & \multicolumn{4}{|l|}{ IN625 } & material- ID: & \\
\hline powder producer / supplier: & \multicolumn{4}{|l|}{ EOS } & LOT-no.: & M111201 \\
\hline powder condition: & virgin & $\mathrm{x}$ & used & others: & \multicolumn{2}{|c|}{$50 / 50$ (virgin/1x used) } \\
\hline \multicolumn{7}{|l|}{ size fraction $[\mu \mathrm{m}]$ : } \\
\hline \multicolumn{7}{|l|}{ name material setup M270: } \\
\hline layer thickness $[\mu \mathrm{m}]$ : & $20 / 40$ & & & & & \\
\hline
\end{tabular}

Atmosphere:

\begin{tabular}{|l|l|l|l|l|}
\hline build gas atmosphere: & $\mathrm{X}$ & nitrogen / generator & argon 4.6/5.0 \\
\hline
\end{tabular}

Exposure parameter setup:
\begin{tabular}{|l|l|l|l|l|l|}
\hline name exposure parameter: & \multicolumn{2}{|l|}{} \\
\hline strategy: & \multicolumn{1}{|l|}{ skin } & $\mathrm{x}$ & skin / core \\
\hline skin thickness: & $\mathrm{xy}(\mathrm{mm})$ & 0.1 or $250 \mathrm{~mm}$ & $\mathbf{z}(\mathrm{mm})$ & 0.1 or $250 \mathrm{~mm}$ \\
\hline
\end{tabular}

Recoater setup:

\begin{tabular}{|l|l|l|l|l|l|}
\hline kind of recoater blade: & \multicolumn{3}{|l|}{ ceramic } & x & HSS \\
\hline recoater charge factor [\%]: & MIN: & 100 & MAX: & 100 \\
\hline
\end{tabular}




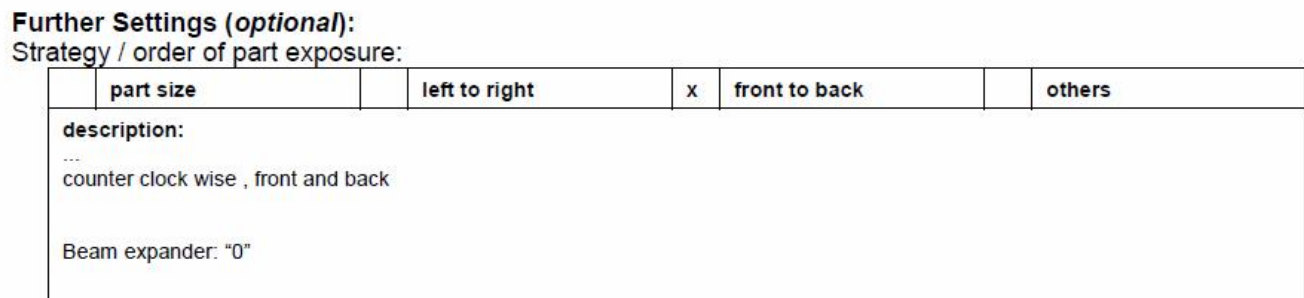

\section{Setting of exposure parameters:}

\begin{tabular}{|c|l|c|c|c|c|}
\hline \multicolumn{2}{|c|}{ order / name of parameter } & $\begin{array}{c}\text { scan speed } \\
{[\mathrm{mm} / \mathrm{sec} .]}\end{array}$ & $\begin{array}{c}\text { laser power } \\
{[\mathrm{W}]}\end{array}$ & $\begin{array}{c}\text { focus } \\
{[\mathrm{mm}]}\end{array}$ & $\begin{array}{c}\text { hatch } \\
{[\mathrm{mm}]}\end{array}$ \\
\hline 1. & $\ldots$ See drawing: direction for PBF build & $\ldots$ & $\ldots$ & $\ldots$ & \\
\hline 2. & $\ldots$ & $\ldots$ & $\ldots$ & $\ldots$ & \\
\hline 3. & $\ldots$ & $\ldots$ & $\ldots$ & $\ldots$ & $\ldots$ \\
\hline 4. & $\ldots$ & $\ldots$ & $\ldots$ & $\ldots$ & \\
\hline & $\ldots$ & $\ldots$ & $\ldots$ & $\ldots$ & \\
\hline
\end{tabular}

Time of build operations:

\begin{tabular}{|l|l|l|l|}
\hline start pre-flooding: AM/PM & $8: 15 \mathrm{AM}$ & \multicolumn{2}{|l|}{} \\
\hline start job: AM/PM & $8: 45 \mathrm{AM}$ & real build time [hh:mm]: & $\ldots$ \\
\hline estimated build time [hh:mm] & $17: 17: 58$ & \multicolumn{3}{|l|}{} \\
\hline
\end{tabular}

Notes / observation during the build: observation:

\section{Observation on part/s:} observation:
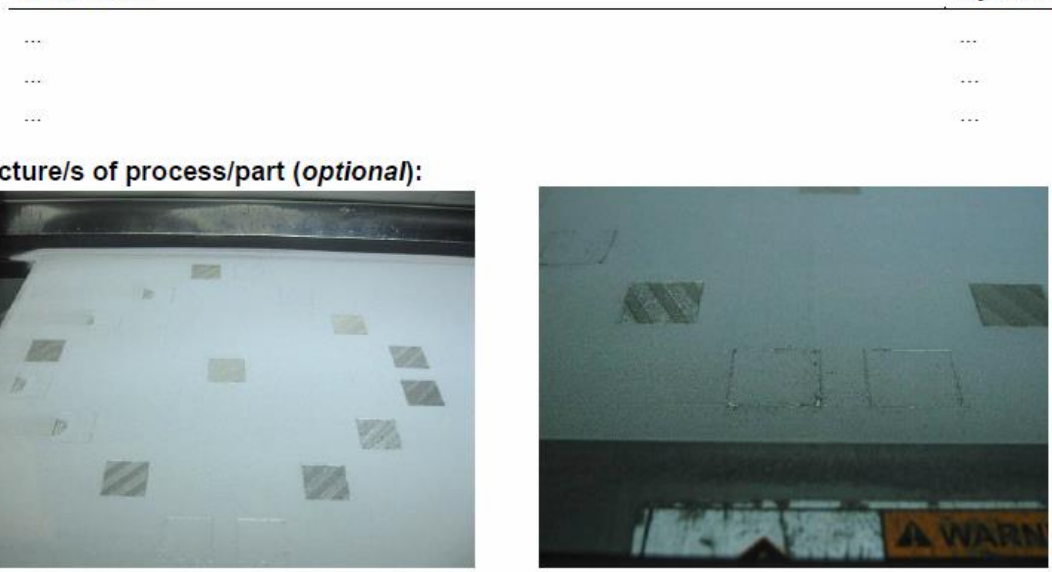

page $2 / 2$ 


\section{Appendix C: Build Drawing and Build Report for Build \#17-16}
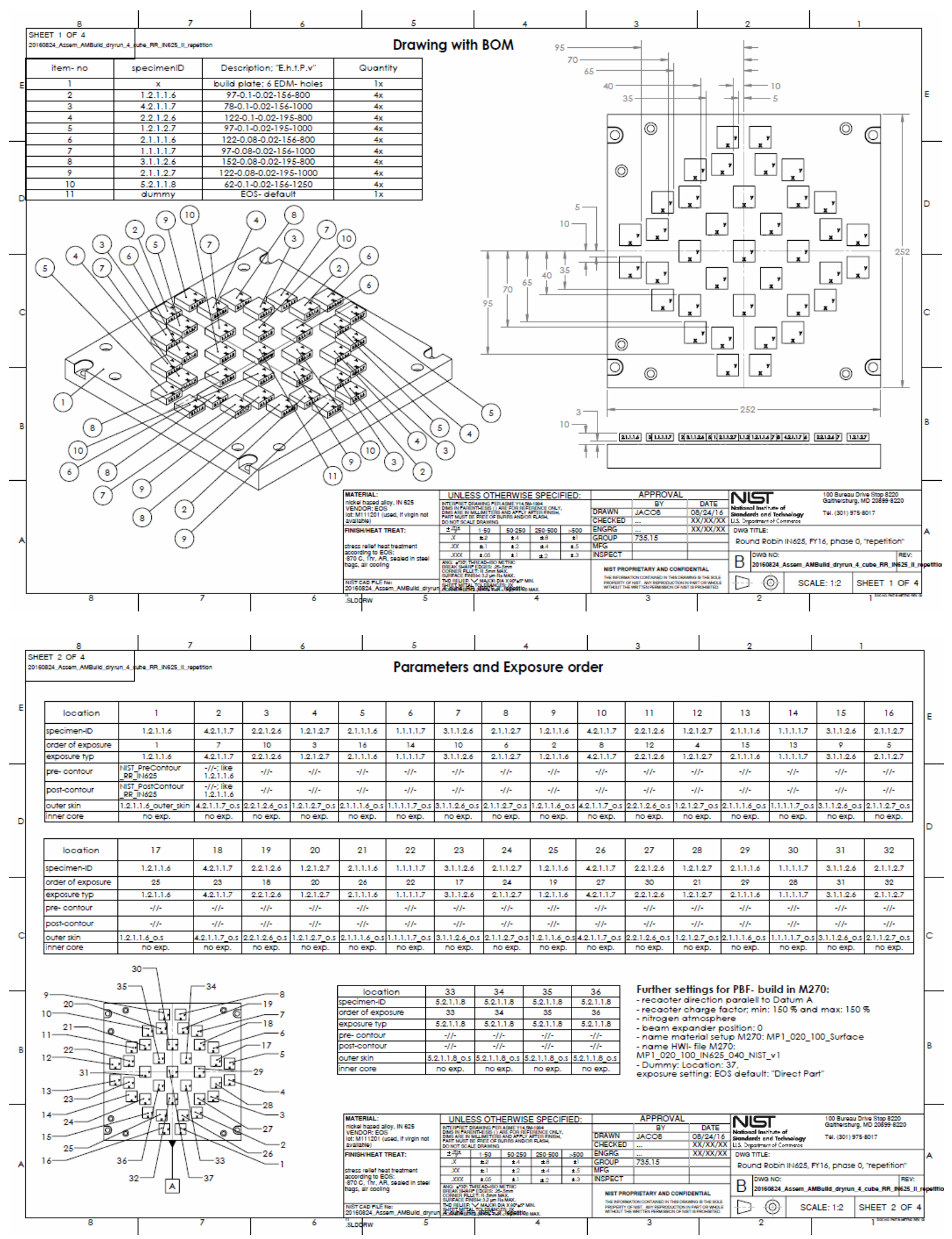

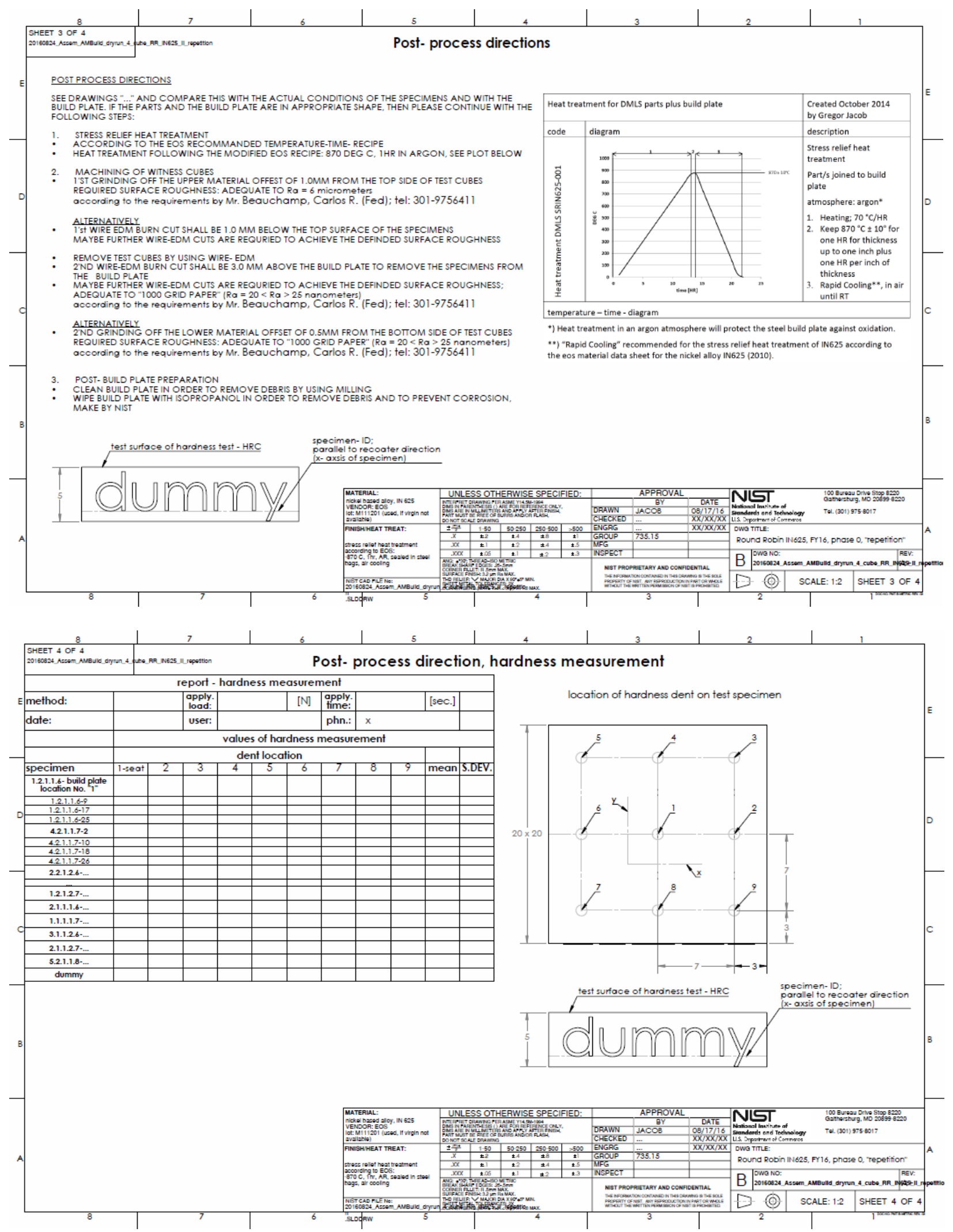


\begin{tabular}{|c|c|c|}
\hline $\begin{array}{l}\text { NIST/ } \\
\text { National Institute of } \\
\text { Standards sand Technology } \\
\text { U.s. Department of Commerce }\end{array}$ & $\begin{array}{c}\text { build job - log } \\
\text { EOS - M270 } \\
\text { EOS LABORATORY }\end{array}$ & $\begin{array}{l}2016 \\
08 / 31\end{array}$ \\
\hline
\end{tabular}

Build job end:

\begin{tabular}{|l|l|l|l|l|}
\hline build successfully finished: & $\mathrm{x}$ & yes & no \\
\hline
\end{tabular}

Project registration:

\begin{tabular}{|l|l|c|}
\hline project name: & $\begin{array}{l}\text { Round Robin IN625, FY2016 } \\
\text { "36 cube build" }\end{array}$ & $\begin{array}{c}\text { build- no.: } \\
0017-16\end{array}$ \\
\hline build file name: & $0017-16 \_$AM_Round_Robin_FY16_phase0_repetition \\
\hline \multicolumn{2}{|l|}{} \\
\hline description (short): & Parameter study-repetition
\end{tabular}

Operator registration:

name:

Gregor and Mike

\begin{tabular}{|l|l} 
extension: & $\mathrm{X} 8017$
\end{tabular}

Description of part/s to build:

\begin{tabular}{|l|l|l|l|}
\hline $\begin{array}{l}\text { name build element/s: } \\
\text { (sketch) }\end{array}$ & quantity: & $36+1$ \\
& $\begin{array}{l}\text { Cubes } \\
\text { 9 different settings of power, hatch and } \\
\text { velocity with 4 replicas of each setting } \\
\text { Plus: } \\
\text { One dummy (EOS default; direct part) }\end{array}$ & $\ldots$ \\
\hline $\begin{array}{l}\text { dimension of element/s } \\
\text { h/w/d [mm]: }\end{array}$ & $20 \times 20 \times 7$ plus $3 \mathrm{~mm}$ support & $\ldots$ \\
\hline
\end{tabular}

Build plate:

\begin{tabular}{|l|l|l|l|l|l|}
\hline build plate no: & $\ldots$ & x & EOS; $250 \times 250 \mathrm{~mm}$ & \multicolumn{3}{l|}{ regular plate } \\
\hline thickness [mm] & $\ldots$ & & NIST; $4 \times: 100 \times 100 \mathrm{~mm}$ & \multicolumn{3}{|l|}{ experimental plate } \\
\hline EDM holes & \multicolumn{2}{|l|}{ no } & x & yes \\
\hline temperature [celcius] & pre-heat: & 80 & build: & 80 \\
\hline
\end{tabular}

Material:

\begin{tabular}{|c|c|c|c|c|c|}
\hline material : & \multicolumn{3}{|c|}{ Nickel base alloy } & material- ID: & Inconel 625 \\
\hline powder producer / supplier: & \multicolumn{3}{|l|}{ EOS } & LOT-no.: & M111201 \\
\hline powder condition: & virgin & \begin{tabular}{l|l}
$\mathrm{x}$ & used \\
\end{tabular} & others: & & \\
\hline \multicolumn{6}{|l|}{ size fraction $[\mu \mathrm{m}]:$} \\
\hline name material setup M270: & \multicolumn{5}{|c|}{ MP1_020_100_IN625_040_NIST_v1 } \\
\hline layer thickness $[\mu \mathrm{m}]$ : & \multicolumn{5}{|l|}{20} \\
\hline
\end{tabular}

Atmosphere:

\begin{tabular}{|l|l|l|l|l|}
\hline build gas atmosphere: & $\mathrm{x}$ & nitrogen / generator & argon 4.6/5.0 \\
\hline
\end{tabular}

Exposure parameter setup:

\begin{tabular}{|l|l|l|l|l|}
\hline name exposure parameter: & \multicolumn{4}{|l|}{ See drawings } \\
\hline strategy: & $\mathrm{x}$ & skin & \multicolumn{2}{l|}{ skin / core } \\
\hline skin thickness: & $\mathrm{xy}(\mathrm{mm})$ & 250 & $\mathbf{z}(\mathrm{mm})$ & 250 \\
\hline
\end{tabular}

Recoater setup:

\begin{tabular}{|l|l|l|l|l|l|}
\hline kind of recoater blade: & \multicolumn{2}{|l|}{ ceramic } & X & HSS & \\
\hline recoater charge factor [\%]: & MIN: & 150 & MAX: & 150 \\
\hline
\end{tabular}


Further Settings (optional)

Strategy / order of part exposure:

\begin{tabular}{|l|l|l|l|l|l|}
\hline \multicolumn{1}{|l|}{ part size } & left to right & $\mathrm{x}$ & front to back & $\mathrm{x}$ & others \\
\hline $\begin{array}{l}\text { description: } \\
\text { alternating between front and back counter clockwise with } 90 \text { degree steps every } 3^{\text {rd }} \text { specimen } \\
\text { beam expander: } 0\end{array}$
\end{tabular}

Setting of exposure parameters:

\begin{tabular}{|c|c|c|c|c|c|c|}
\hline location & Specimen - ID & Order & $\begin{array}{c}\text { scan speed } \\
{[\mathrm{mm} / \mathrm{sec} .]}\end{array}$ & $\begin{array}{c}\text { laser power } \\
{[\mathrm{W}]}\end{array}$ & $\begin{array}{l}\text { focus } \\
{[\mathrm{mm}]}\end{array}$ & $\begin{array}{l}\text { hatch } \\
{[\mathrm{mm}]}\end{array}$ \\
\hline 1. & 1.2.1.1.6 Cube $\left(E=97 \mathrm{~J} / \mathrm{mm}^{\wedge} 3\right)$ & 1 & 800 & 156 & 0.1 & 0.1 \\
\hline 2. & 4.2.1.1.7 Cube $\left(E=78 \mathrm{~J} / \mathrm{mm}^{\wedge} 3\right)$ & 7 & 1000 & 156 & 0.1 & 0.1 \\
\hline 3. & 2.2.1.2.6 Cube $\left(\mathrm{E}=122 \mathrm{~J} / \mathrm{mm}^{\wedge} 3\right)$ & 11 & 800 & 195 & 0.1 & 0.1 \\
\hline 4. & 1.2.1.2.7 Cube $\left(E=97 \mathrm{~J} / \mathrm{mm}^{\wedge} 3\right)$ & 3 & 1000 & 195 & 0.1 & 0.1 \\
\hline 5. & 2.1.1.1.6 Cube ( $\left.\mathrm{E}=122 \mathrm{~J} / \mathrm{mm}^{\wedge} 3\right)$ & 16 & 800 & 156 & 0.1 & 0.08 \\
\hline 6. & 1.1.1.1.7 Cube $\left(E=97 \mathrm{~J} / \mathrm{mm}^{\wedge} 3\right)$ & 14 & 1000 & 156 & 0.1 & 0.08 \\
\hline 7. & 3.1.1.2.6 Cube ( $\mathrm{E}=152 \mathrm{~J} / \mathrm{mm}^{\wedge} 3$ ) & 10 & 800 & 195 & 0.1 & 0.08 \\
\hline 8. & 2.1.1.2.7 Cube $\left(E=122 \mathrm{~J} / \mathrm{mm}^{\wedge} 3\right)$ & 6 & 1000 & 195 & 0.1 & 0.08 \\
\hline 9. & 1.2.1.1.6 Cube $\left(E=97 \mathrm{~J} / \mathrm{mm}^{\wedge} 3\right)$ & 2 & 800 & 156 & 0.1 & 0.1 \\
\hline 10. & 4.2.1.1.7 Cube $\left(E=78 \mathrm{~J} / \mathrm{mm}^{\wedge} 3\right)$ & 8 & 1000 & 156 & 0.1 & 0.1 \\
\hline 11. & 2.2.1.2.6 Cube $\left(E=122 \mathrm{~J} / \mathrm{mm}^{\wedge} 3\right)$ & 12 & 800 & 195 & 0.1 & 0.1 \\
\hline 12. & 1.2.1.2.7 Cube $\left(\mathrm{E}=97 \mathrm{~J} / \mathrm{mm}^{\wedge} 3\right)$ & 4 & 1000 & 195 & 0.1 & 0.1 \\
\hline 13. & 2.1.1.1.6 Cube $\left(E=122 \mathrm{~J} / \mathrm{mm}^{\wedge} 3\right)$ & 15 & 800 & 156 & 0.1 & 0.08 \\
\hline 14. & 1.1.1.1.7 Cube $\left(E=97 \mathrm{~J} / \mathrm{mm}^{\wedge} 3\right)$ & 13 & 1000 & 156 & 0.1 & 0.08 \\
\hline 15. & 3.1.1.2.6 Cube $\left(E=152 \mathrm{~J} / \mathrm{mm}^{\wedge} 3\right)$ & 9 & 800 & 195 & 0.1 & 0.08 \\
\hline 16. & 2.1.1.2.7 Cube $\left(E=122 \mathrm{~J} / \mathrm{mm}^{\wedge} 3\right)$ & 5 & 1000 & 195 & 0.1 & 0.08 \\
\hline 17. & 1.2.1.1.6 Cube $\left(E=97 \mathrm{~J} / \mathrm{mm}^{\wedge} 3\right)$ & 25 & 800 & 156 & 0.1 & 0.1 \\
\hline 18. & 4.2.1.1.7 Cube $\left(E=78 \mathrm{~J} / \mathrm{mm}^{\wedge} 3\right)$ & 23 & 1000 & 156 & 0.1 & 0.1 \\
\hline 19. & 2.2.1.2.6 Cube $\left(\mathrm{E}=122 \mathrm{~J} / \mathrm{mm}^{\wedge} 3\right)$ & 18 & 800 & 195 & 0.1 & 0.1 \\
\hline 20. & 1.2.1.2.7 Cube $\left(E=97 \mathrm{~J} / \mathrm{mm}^{\wedge} 3\right)$ & 20 & 1000 & 195 & 0.1 & 0.1 \\
\hline 21. & 2.1.1.1.6 Cube ( $\mathrm{E}=122 \mathrm{~J} / \mathrm{mm}^{\wedge} 3$ ) & 26 & 800 & 156 & 0.1 & 0.08 \\
\hline 22. & 1.1.1.1.7 Cube $\left(E=97 \mathrm{~J} / \mathrm{mm}^{\wedge} 3\right)$ & 22 & 1000 & 156 & 0.1 & 0.08 \\
\hline 23. & 3.1.1.2.6 Cube $\left(E=152 \mathrm{~J} / \mathrm{mm}^{\wedge} 3\right)$ & 17 & 800 & 195 & 0.1 & 0.08 \\
\hline 24. & 2.1.1.2.7 Cube $\left(E=122 \mathrm{~J} / \mathrm{mm}^{\wedge} 3\right)$ & 24 & 1000 & 195 & 0.1 & 0.08 \\
\hline 25. & 1.2.1.1.6 Cube $\left(E=97 \mathrm{~J} / \mathrm{mm}^{\wedge} 3\right)$ & 19 & 800 & 156 & 0.1 & 0.1 \\
\hline 26. & 4.2.1.1.7 Cube $\left(E=78 \mathrm{~J} / \mathrm{mm}^{\wedge} 3\right)$ & 27 & 1000 & 156 & 0.1 & 0.1 \\
\hline 27. & 2.2.1.2.6 Cube $\left(E=122 \mathrm{~J} / \mathrm{mm}^{\wedge} 3\right)$ & 30 & 800 & 195 & 0.1 & 0.1 \\
\hline 28. & 1.2.1.2.7 Cube $\left(E=97 \mathrm{~J} / \mathrm{mm}^{\wedge} 3\right)$ & 21 & 1000 & 195 & 0.1 & 0.1 \\
\hline 29. & 2.1.1.1.6 Cube $\left(E=122 \mathrm{~J} / \mathrm{mm}^{\wedge} 3\right)$ & 29 & 800 & 156 & 0.1 & 0.08 \\
\hline 30. & 1.1.1.1.7 Cube $\left(E=97 \mathrm{~J} / \mathrm{mm}^{\wedge} 3\right)$ & 28 & 1000 & 156 & 0.1 & 0.08 \\
\hline 31. & 3.1.1.2.6 Cube $\left(\mathrm{E}=152 \mathrm{~J} / \mathrm{mm}^{\wedge} 3\right)$ & 31 & 800 & 195 & 0.1 & 0.08 \\
\hline 32. & 2.1.1.2.7 Cube $\left(E=122 \mathrm{~J} / \mathrm{mm}^{\wedge} 3\right)$ & 32 & 1000 & 195 & 0.1 & 0.08 \\
\hline 33. & 5.2.1.1.8 Cube $\left(\mathrm{E}=62 \mathrm{~J} / \mathrm{mm}^{\wedge} 3\right)$ & 33 & 800 & 195 & 0.1 & 0.1 \\
\hline 34. & 5.2.1.1.8 Cube $\left(\mathrm{E}=62 \mathrm{~J} / \mathrm{mm}^{\wedge} 3\right)$ & 34 & 800 & 195 & 0.1 & 0.1 \\
\hline 35. & 5.2.1.1.8 Cube $\left(E=62 \mathrm{~J} / \mathrm{mm}^{\wedge} 3\right)$ & 35 & 800 & 195 & 0.1 & 0.1 \\
\hline 36. & 5.2.1.1.8 Cube $\left(E=62 \mathrm{~J} / \mathrm{mm}^{\wedge} 3\right)$ & 35 & 800 & 195 & 0.1 & 0.1 \\
\hline
\end{tabular}


Time of build operations:

\begin{tabular}{|l|l|l|l|}
\hline start pre-flooding: AM/PM & \multicolumn{3}{|l|}{ 10:30 AM } \\
\hline start job: AM/PM & $11: 45 \mathrm{AM}$ & real build time [hh:mm]: & $\ldots$ \\
\hline estimated build time [hh:mm] & $24 \mathrm{hrs}$ & $\ldots$ \\
\hline
\end{tabular}

Notes / observation during the build:

observation:

build time / layer / height:

Before build was started, powder remained in the Dispenser Bin over the night (12 hrs) with

turned on heating for drying the powder

Position Dispenser at Start: 51.75

Positions Build plate at Start: 4.805

Position Dispenser during build: 43.62

Positions Build plate during build: 1.925

Position Dispenser during build: 41.13

Positions Build plate during build: 1.042

Position Dispenser at build finished: 23.45

Positions Build plate at build finished: -5.215

\section{Observation on part/s:}

observation:

layer / height:

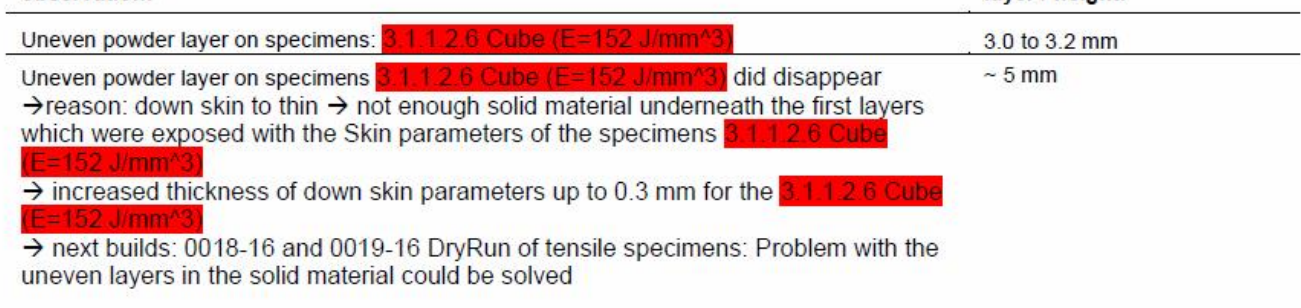

Picture/s of process/part (optional):

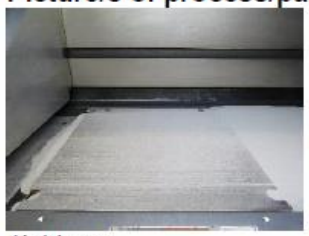

1'st layer

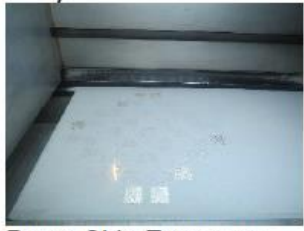

Down Skin Exposure
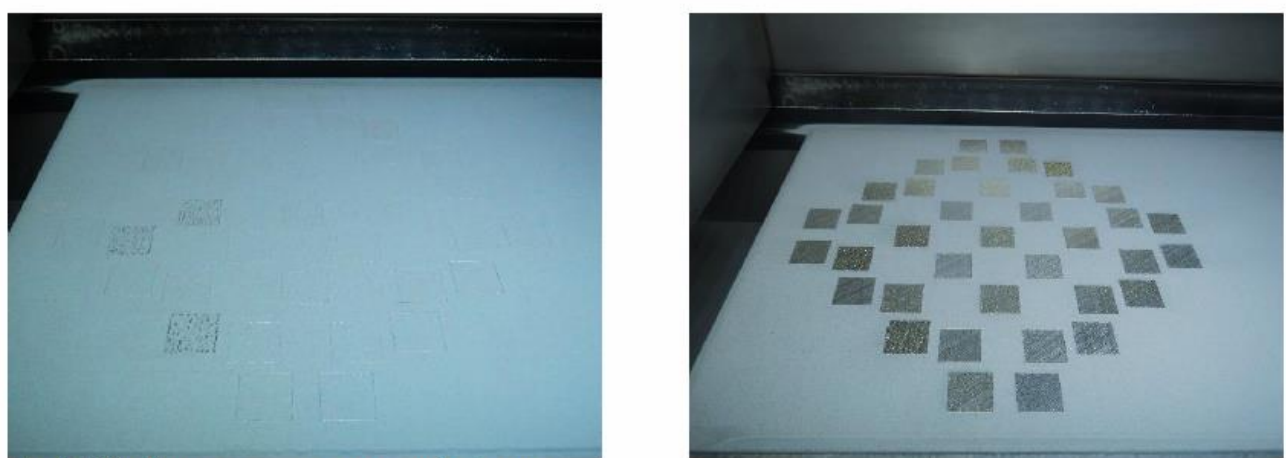

Begin Skin Exposure: uneven powder layers on specimens 


\section{Appendix D: The Effect of Block Thickness on Hardness Measurements}

Due to the variations in the EDM process to separate the blocks from the build platform, the thickness of the blocks for Build \#17-16 varied within $1.3 \mathrm{~mm}$. The effect of the thickness variation on the hardness measurements was investigated as a source of uncertainty. The measured hardness of each block was compared to its 'relative thickness,' which is defined as the difference of the thickness of the block from the thickness of the reference (dummy) block.

The block relative thickness ranged from 0.656 to 1.281 (Figure D.1) for Build \#1716 due to the EDM process and was treated as a continuous quantity while performing the statistical analysis.

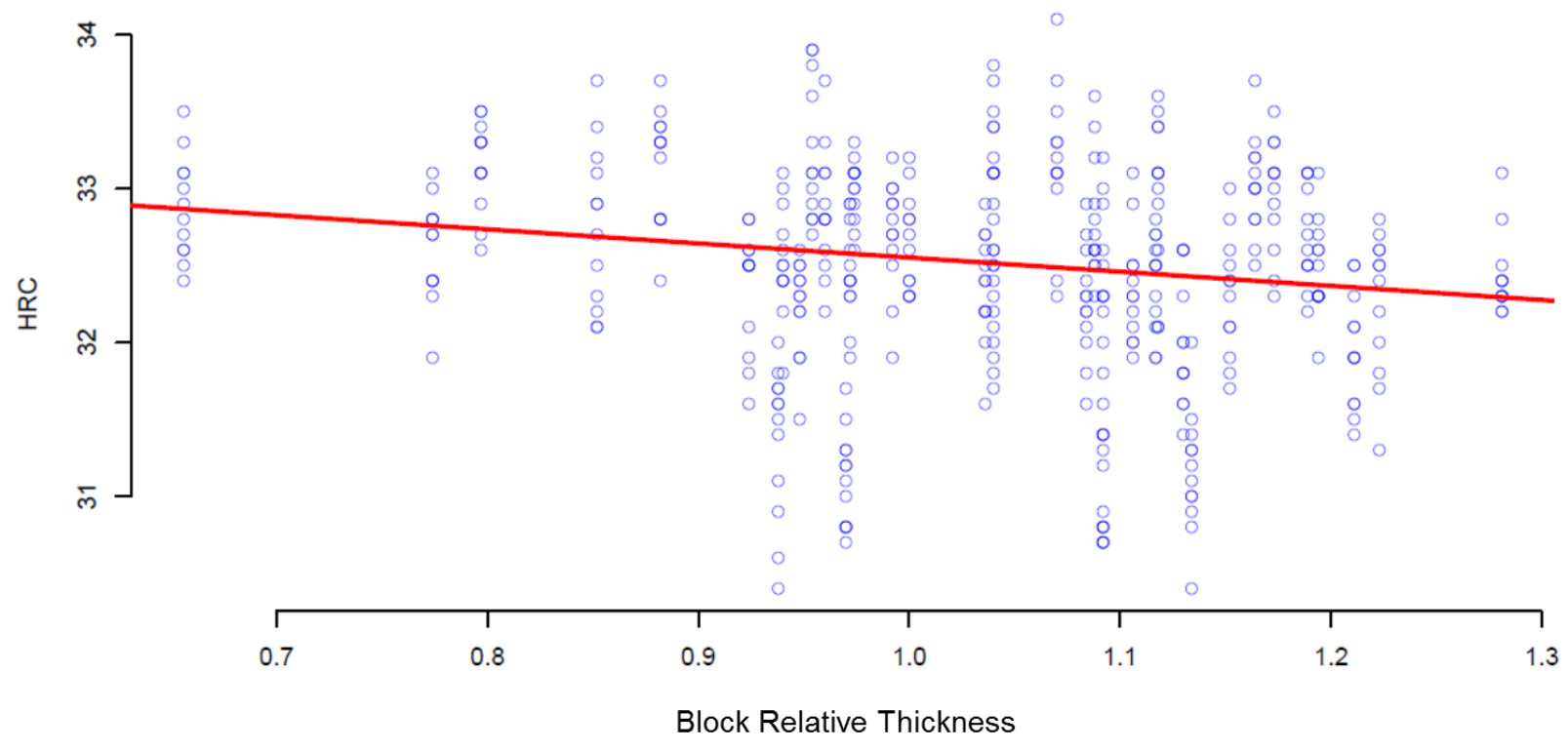

Figure D.1 - The relationship between measured hardness and block relative thickness.

Even though Figure D.1 shows considerable scatter around the linear trend, depicted as a red line sloping down from left to right, this trend is statistically significant, with an estimated slope of -0.9 HRC per unit of block relative thickness, and a standard uncertainty of 0.2 HRC per unit of block relative thickness. The trend was estimated by robust regression, using the M-estimator implemented in $\mathrm{R}$ [14] and the rlm function defined in package MASS [15]. This trend is the result of the stress field created under the indenter 
while performing the test reaching the bottom of the sample. The manner and extent of the effect on the measured hardness when the sample is thinner than the thickness required for the containment, is dependent on the material under testing and, for this case, was initially estimated to be smaller than $8 \mathrm{~mm}$. 


\section{Appendix E: Microstructure of Manufactured Material}

\section{Unetched Microstructure}

Figure E.1 shows examples of bright-field microscopy images of four unetched IN625 manufactured blocks from Build \#2-16 and Build \#3-16 after stress relief heat treatment (blocks 1.2.1.1.6, 1.2.1.2.7, 3.1.1.2.6, and 2.2.1.2.6). The XZ plane is the viewing surface, and the positive $\mathrm{Y}$ axis is into the page. The positive $\mathrm{Z}$ axis is the build direction. No microstructure is visible except for small black 'pits', which are small pores in the material. The blocks were sectioned to expose an internal $\mathrm{XZ}$ plane and polished according to standard metallographic procedures [18].

The image for block 3.1.1.2.6 (Figure E.1, bottom left) shows the sectioned surface of the block manufactured with a reduced hatch distance $(0.08 \mathrm{~mm})$ and correspondingly higher energy density $\left(152.3 \mathrm{~J} / \mathrm{mm}^{3}\right.$ ). The image for block 1.2.1.1.6 (Figure E.1, top left) shows the sectioned surface of the block for reduced laser power $(156 \mathrm{~W})$ and correspondingly lower energy density $\left(97.5 \mathrm{~J} / \mathrm{mm}^{3}\right)$. Both surfaces appear to have a small number of exposed pores, and also the smallest-sized pores. It is interesting to note that the images from 2.2.1.2.6 (Figure E.1, bottom right) with the recommended settings (laser power $195 \mathrm{~W}$, hatch distance $0.1 \mathrm{~mm}$, and energy density of $122 \mathrm{~J} / \mathrm{mm}^{3}$ ) had the highest density of pores but the pores were also consistently small.

The images from block 1.2.1.2.7 (Figure E.1, top right) had a small number of pores, but there was at least one pore that was substantially larger than those observed from the other settings. This material was manufactured with a higher laser scan speed $(1000 \mathrm{~mm} / \mathrm{s})$ and correspondingly a lower energy density $\left(97.5 \mathrm{~J} / \mathrm{mm}^{3}\right)$. It is possible that the higher scan speed and lower energy density resulted in the occasional large pore by not creating an ideal melt pool. The average hardness values from these four blocks was approximately $36 \mathrm{HRC}$. 


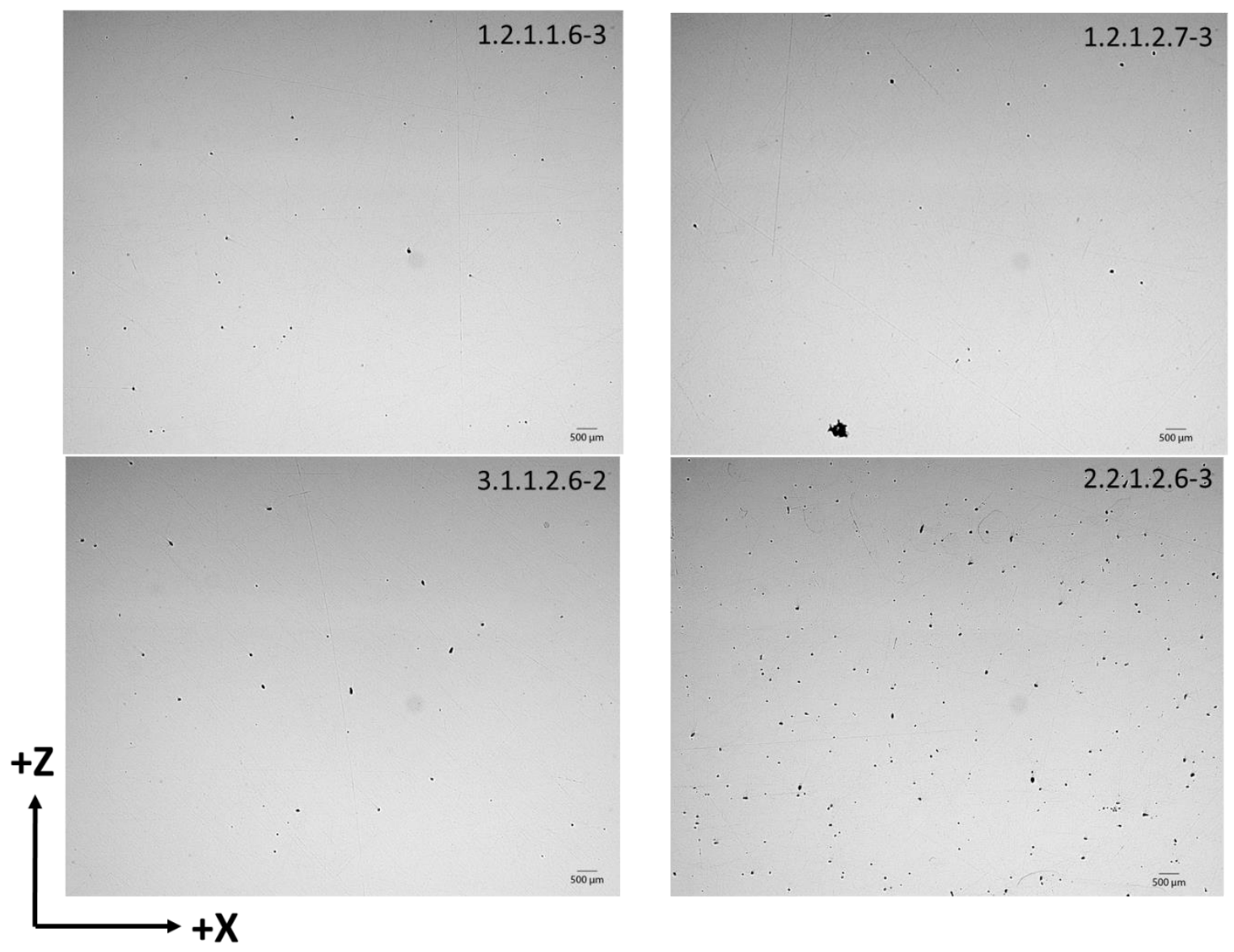

Figure E.1 - Top left, block 1.2.1.1.6 (laser power was reduced to $156 \mathrm{~W}$, energy density $\left(E_{\mathrm{D}}\right)=97.5 \mathrm{~J} / \mathrm{mm}^{3}$ ). Top right, block 1.2.1.2.7 (scan speed was increased to $1000 \mathrm{~mm} / \mathrm{s}$, $E_{\mathrm{D}}=97.5 \mathrm{~J} / \mathrm{mm}^{3}$ ). Bottom left, block 3.1.1.2.6 (hatch distance was reduced to $0.08 \mathrm{~mm}$, $E_{\mathrm{D}}=152.3 \mathrm{~J} / \mathrm{mm}^{3}$ ). Bottom right, block 2.2.1.2.6 (hatch distance $=0.1 \mathrm{~mm}$, laser power $=195 \mathrm{~W}$, scan speed $\left.=800 \mathrm{~mm} / \mathrm{s}, E_{\mathrm{D}}=121.9 \mathrm{~J} / \mathrm{mm}^{3}\right)$.

\section{Etched Microstructure}

Metallographic analysis was performed after etching the same four blocks (1.2.1.1.6, 1.2.1.2.7, 3.1.1.2.6, and 2.2.1.2.6) with aqua regia (20 $\mathrm{mL} \mathrm{HNO}_{3}$ in $60 \mathrm{~mL}$ of $\left.\mathrm{HCl}\right)$. The contrast in the images was primarily produced by the variations in crystal orientation (Figure E.2). The axes are the same as Figure E.1 with the positive Y axis going into the page. The scale is noted in the bottom right corner. 
Both the grain structure and the melt pools are visible in the images. The grain shape is generally columnar with the long axis of the grains primarily in the build direction $(\mathrm{Z}$ axis). This is representative of a dendritic solidification microstructure. The grain size varies significantly among the different blocks. Based on the limited number of blocks, there is no clear correlation between the parameter settings used to manufacture the blocks and the following: 1) melt pool depth, 2) grain size and grain shape, or 3) porosity count and porosity size. It is also not clear if the grain structure is more visible in some images because of a variation in the local etching conditions or because of the change in parameter settings. A more extensive specimen selection with morphology measurements would be required to make such correlations, but this is beyond the scope of this study.
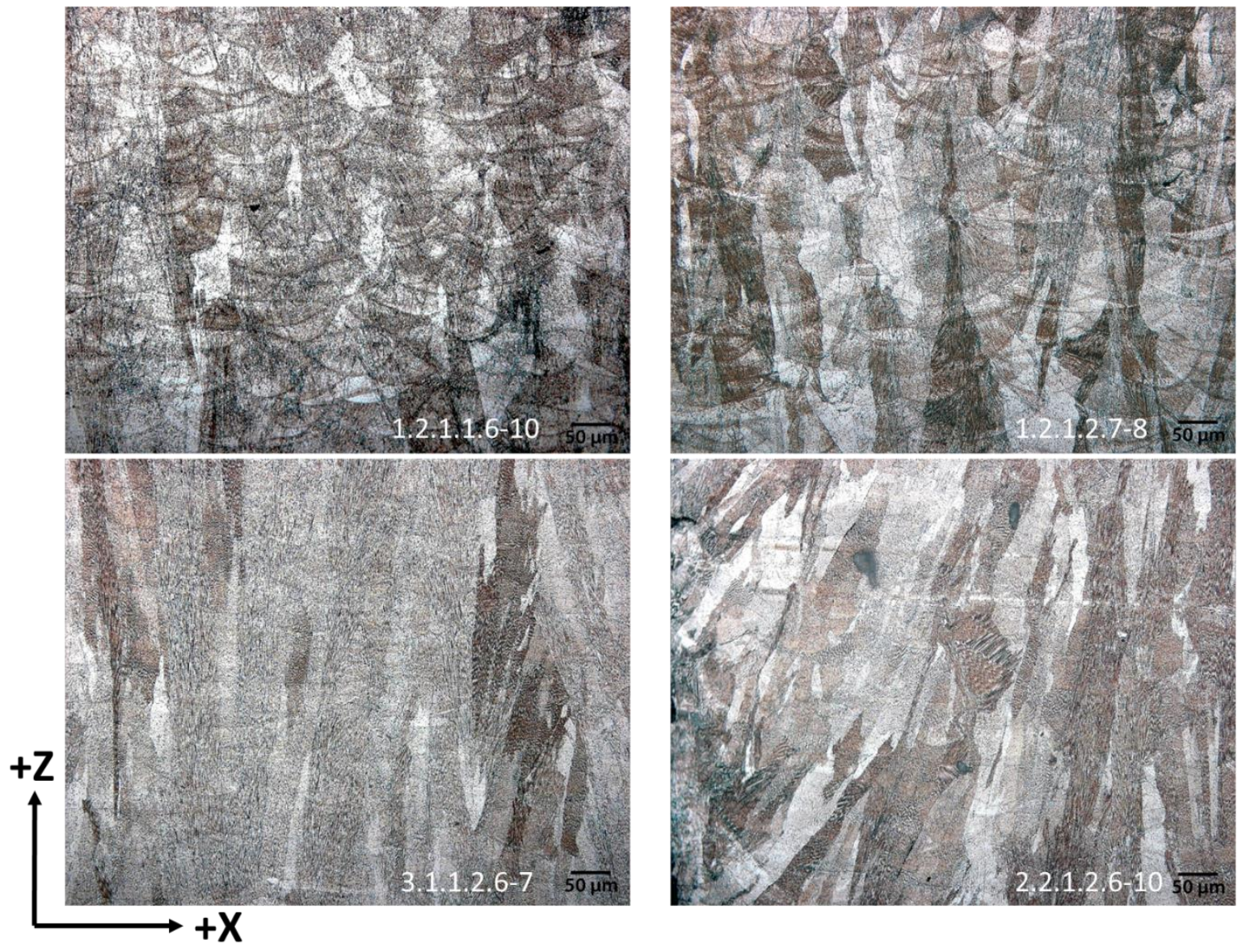

Figure E.2 - Top left, block 1.2.1.1.6 (laser power was reduced to $156 \mathrm{~W}, E_{\mathrm{D}}=97.5 \mathrm{~J} / \mathrm{mm}^{3}$ ). Top right, block 1.2.1.2.7 (scan speed was increased to $1000 \mathrm{~mm} / \mathrm{s}, E_{\mathrm{D}}=97.5 \mathrm{~J} / \mathrm{mm}^{3}$ ). 
Bottom left, block 3.1.1.2.6 (hatch distance was reduced to $0.08 \mathrm{~mm}, E_{\mathrm{D}}=152.3 \mathrm{~J} / \mathrm{mm}^{3}$ ).

Bottom right, block 2.2.1.2.6 (recommended settings, hatch distance $=0.1 \mathrm{~mm}$,

laser power $=195 \mathrm{~W}$, scan speed $\left.=800 \mathrm{~mm} / \mathrm{s}, E_{\mathrm{D}}=121.9 \mathrm{~J} / \mathrm{mm}^{3}\right)$. 